\title{
Reflectance spectra of synthetic Fe-free ortho- and clinoenstatites in the UV/ VIS/IR and implications for remote sensing detection of Fe-free pyroxenes on planetary surfaces
}

\author{
Kathrin Markus a,b, , Lyuba Moroz ${ }^{\text {c, a }}$, Gabriele Arnold ${ }^{\text {a }}$, Daniela Henckel ${ }^{\text {a,d }}$, Harald Hiesinger ${ }^{\text {b }}$, \\ Arno Rohrbach ${ }^{\mathrm{e}}$, Stephan Klemme ${ }^{\mathrm{e}}$ \\ ${ }^{a}$ DLR, Institut für Planetenforschung, Berlin, Germany \\ ${ }^{\mathrm{b}}$ Institut für Planetologie, Westfälische Wilhelms-Universität Münster, Germany \\ ${ }^{\mathrm{c}}$ Institut für Erd- und Umweltwissenschaften, University of Potsdam, Potsdam, Germany \\ ${ }^{\mathrm{d}}$ Institut für Geologische Wissenschaften, Freie Universität Berlin, Germany \\ e Institut für Mineralogie, Westfälische Wilhelms-Universität Münster, Germany
}

\section{A R T I C L E I N F O}

\section{Keywords:}

Reflectance spectroscopy

Remote sensing

Enstatite

Synthetic pyroxene

Analog material

\begin{abstract}
A B S T R A C T
For a better spectral characterization of planetary bodies with enstatite-rich surfaces like Mercury or E-type asteroids, we synthesized two different enstatite $\left(\mathrm{Mg}_{2} \mathrm{Si}_{2} \mathrm{O}_{6}\right)$ polymorphs: Orthoenstatite and clinoenstatite. Both enstatite polymorphs are known from the meteorite record and are commonly observed in aubrites and enstatite chondrites. The synthesized enstatites are particulate samples suitable for laboratory reflectance measurements and can be used for compositional modelling by preparing mixtures of samples in the laboratory or by using the sample's spectra in mathematical models. We report on the synthesis process, chemical composition, grain size distribution, and reflectance spectra of these synthetic enstatites covering the wavelength range from 0.25 to $17 \mu \mathrm{m}$, compare them to other pyroxenes (meteoritic enstatite and other synthetic enstatites and diopside), and discuss the implications of retrieving surface compositions of planetary bodies like E-type asteroids, comets, or Mercury.

Both enstatite spectra are very bright in the VIS and NIR and show almost neutral to slightly bluish spectral slopes with a steep absorption in the UV. Very low iron in the enstatites (below $\sim 0.04 \mathrm{wt} \% \mathrm{FeO}$ ) already results in weak albeit noticeable absorptions in the VNIR between 0.4 and $0.9 \mu \mathrm{m}$. Orthoenstatite and clinoenstatite are not distinguishable based only on their spectra in the VIS and NIR. At the Reststrahlen bands in the MIR a systematic difference in the number and exact position of local minima at $\sim 10 \mu \mathrm{m}$ between clinoenstatite and orthoenstatite is evident. This can be used to discern between the polymorphs in this wavelength range. Additionally, we can distinguish between Fe-free low- and high-Ca pyroxenes in the MIR.
\end{abstract}

\section{Introduction}

For a better understanding of Fe-poor planetary bodies the availability of laboratory spectra of Fe-free silicates as analog materials are crucial but terrestrial samples of enstatite usually contain several mol\% of $\mathrm{FeO}$ with almost pure enstatite being extremely rare (Robinson, 1980). For easy availability of larger amounts of pure ortho- and clinoenstatite we modified a technique for synthesis of enstatite described by Sarver and Hummel (1962). The advantage of our method is the synthesis of larger quantities in air in a furnace without having to apply high pressures. This makes our method easily applicable in different laboratories.
The resultant enstatite samples can be used as analog materials for laboratory studies, e.g., for producing mixtures with other mineral samples. We investigate the spectral characteristics of the clinoenstatite and orthoenstatite from the near UV at $0.25 \mu \mathrm{m}$ to the MIR at $17 \mu \mathrm{m}$ and compare the spectra of our enstatites to the spectra of several other pyroxenes including meteoritic orthoenstatite and synthetic orthoenstatites, clinoenstatite, and diopside. We demonstrate possibilities to discriminate between orthoenstatite and clinoenstatite based on the observed spectral characteristics and between low-Ca low-Fe and high-Ca low-Fe pyroxenes in different spectral ranges. Furthermore, we discuss the implications of our findings for the analysis and interpretation of

\footnotetext{
* Corresponding author. Institut für Planetologie, Westfälische Wilhelms-Universität Münster, Germany.

E-mail address: kathrin.markus@uni-muenster.de (K. Markus).
} 
remote sensing spectra of solar system bodies.

Mineralogical and compositional information can be obtained remotely by means of reflectance spectroscopy (e.g., Clark, 1999; Pieters and Englert, 1993). Major rock-forming minerals like pyroxenes are very common in the Solar System and show characteristic absorption bands due to $\mathrm{Fe}^{2+}$ in the VIS and NIR (e.g., Burns, 1993a; Klima et al., 2007). The Fe-free low-Ca pyroxene endmember enstatite is a common mineral endmember on planetary and small body surfaces like some asteroids and Mercury (e.g., Nittler et al., 2011; Stockstill-Cahill et al., 2012; Weider et al., 2012) and a major constituent of meteorites like aubrites (Keil, 2010) and enstatite chondrites (Mason, 1966, 1968). Enstatites in aubrites and enstatite chondrites are Fe-free, indicating the formation under reducing conditions (Keil, 2010). Reflectance spectra of these meteorites as well as the enstatite-rich or generally $\mathrm{Fe}^{2+}$-poor asteroids like an asteroidal target of the ESA Rosetta mission (2867) Šteins (Keller et al., 2010) are often featureless in the VIS and NIR lacking the absorption features associated with iron incorporated into the crystal structure of silicates. Enstatite is also present in comets known from IDPs of presumably cometary origin (Messenger et al., 2003) and the dust of comet 81P/Wild 2 collected by the Stardust mission (Brownlee et al., 2006; Zolensky et al., 2006). Zolensky et al. (2006) reported compositional ranges of orthopyroxenes from $\mathrm{En}_{52}$ to $\mathrm{En}_{100}$. The majority of all analyzed low-Ca pyroxenes has compositions between $\mathrm{En}_{90}$ and $\mathrm{En}_{100}$. Ground-based IR observations of comets also indicate that Fe-free or Fe-poor enstatite is a major crystalline silicate component of cometary dust (Hanner, 1999; Harker et al., 2002; Wooden et al., 2000, 2005). Silicates on Mercury are reported to contain only very small amounts of $\mathrm{Fe}^{2+}$. Fe-poor minerals, e.g., enstatite, likely dominate the silicate portion of Mercury's surface (e.g., Izenberg et al., 2014; Nittler et al., 2011; Stockstill-Cahill et al., 2012; Weider et al., 2012; Zolotov et al., 2013). Stockstill-Cahill et al. (2012) concluded from analyses of elemental abundances and ratios derived by the X-ray Spectrometer (XRS) on MESSENGER that the surface of Mercury consists mainly of Mg-rich orthopyroxene and plagioclase. In addition, the absence of detectable absorption bands in NIR reflectance spectra support the presence of Fe-poor silicate minerals. For example, Izenberg et al. (2014) reported the absence of any absorption feature near $1 \mu \mathrm{m}$. Even in fresh not space-weathered exposures, they could not detect a clear $1 \mu \mathrm{m}$ band in MESSENGER's Mercury Atmospheric and Surface Composition Spectrometer (MASCS) spectra. Izenberg et al. (2014) concluded from spectral modeling with regard to the detectability of the absorption band at $1 \mu \mathrm{m}$ that the iron content in silicates on the surface of Mercury cannot be greater than $\sim 1.4 \mathrm{wt} \% \mathrm{Fe}^{2+}$ or $\sim 1.8 \mathrm{wt} \% \mathrm{FeO}$. The spectral characteristics of orthoenstatite and clinoenstatite in the MIR allows discrimination between these two polymorphs in spectral data. Orthoenstatite and clinoenstatite form under different thermal conditions. The possibility to spectrally distinguish between these two polymorphs on planetary surfaces therefore allows one to discuss the thermal and shock history of these surfaces. Future applications of this technique could include data from the MErcury Radiometer and Thermal Infrared Spectrometer (MERTIS) instrument onboard ESA's BepiColombo mission covering the wavelength range between 7 and $14 \mu \mathrm{m}$ (Hiesinger et al., 2010).

Fe-bearing orthopyroxenes show diagnostic absorption bands centered near 0.9-0.94 $\mu \mathrm{m}$ (Band I) and 1.8-2.1 $\mu \mathrm{m}$ (Band II). While systematic changes in positions and depths of these bands as a function of Fe- and Ca-contents in pyroxenes have been extensively studied (e.g., Adams, 1974; Cloutis and Gaffey, 1991; Hazen et al., 1978; Klima et al., 2007, 2011), almost Fe-free enstatite has, so far, only been spectroscopically investigated by Klima et al. (2007). Their synthetic enstatite sample $\mathrm{En}_{100}$ with only $0.06 \mathrm{wt} \% \mathrm{FeO}$ (with $66 \%$ of the iron being $\mathrm{Fe}^{3+}$ ) shows a weak absorption band at $\sim 0.9 \mu \mathrm{m}$ but does not show the absorption Band II, while another synthetic sample En $\mathrm{E}_{97.5}$ with $1.83 \mathrm{wt} \%$ $\mathrm{FeO}$ already exhibits deep absorptions centered at $0.906 \mu \mathrm{m}$ and $1.799 \mu \mathrm{m}$ (Klima et al., 2007). Spectral properties of enstatite change with increasing amount of Fe incorporated into the crystal structure. With increasing amount of $\mathrm{Fe}^{2+}$ the band centers are shifted to longer wavelengths and the bands become deeper (Adams, 1974; Cloutis and Gaffey, 1991).

The absorption bands in pyroxenes in the NIR arise from Fe incorporated in the two different crystallographic positions M1 and M2 (Burns, 1993a; b). In Mg-rich orthopyroxenes $\mathrm{Fe}^{2+}$ is enriched in the M2-site resulting in the strong absorption bands I and II. With increasing $\mathrm{Fe}^{2+}$ amount the absorption bands are shifted to longer wavelengths (Adams, 1974; Cloutis and Gaffey, 1991). The intense absorption due to $\mathrm{Fe}^{2+}$ in $\mathrm{M} 2$ sites overlap the much weaker absorption bands resulting from $\mathrm{Fe}^{2+}$ in $\mathrm{M} 1$ sites. The absorption bands at $0.98 \mu \mathrm{m}$ and $1.2 \mu \mathrm{m}$ due to $\mathrm{Fe}^{2+}$ in $\mathrm{M} 1$ sites are less intense than the $\mathrm{Fe}^{2+} / \mathrm{M} 2$ absorption bands because of the M1 site being less distorted than the M2 site (Burns, 1993a; b). $\mathrm{Fe}^{3+}$ in the octahedral positions shows absorptions bands due to spin-forbidden crystal field transitions. Two weak and broad absorptions bands in many silicates resulting from $\mathrm{Fe}^{3+}$ are located at $0.6 \mu \mathrm{m}$ and $0.9 \mu \mathrm{m}$ and another stronger band at $\sim 0.44 \mu \mathrm{m}$ (Burns, 1993b). Absorption bands due to spin-forbidden transitions within $\mathrm{Fe}^{3+}$ ions are generally weaker than spin-allowed transitions due to $\mathrm{Fe}^{2+}$ in silicates. Spin-forbidden $\mathrm{Fe}^{2+}$ features are stronger than spin-forbidden $\mathrm{Fe}^{3+}$ bands. Wavelengths positions of spin-forbidden $\mathrm{Fe}^{2+}$ bands are summarized in Klima et al. (2007). Some weaker absorption bands also occur due to metal-metal intervalence charge transfer (IVCT), when a $3 \mathrm{~d}$ electron is transferred from one cation to a neighboring cation. These absorption bands are typically located between $0.54 \mu \mathrm{m}$ and $1 \mu \mathrm{m}$ (Burns, 1993a; b).

In the UV, pyroxenes show intense Fe-O charge transfer bands from both $\mathrm{Fe}^{2+}$ and $\mathrm{Fe}^{3+}$. Generally the $\mathrm{Fe}^{3+}-\mathrm{O}$ charge transfer bands are stronger than the $\mathrm{Fe}^{2+}-\mathrm{O}$ bands by about two orders of magnitude and result in a sharp drop in reflectance at wavelength $<0.5 \mu \mathrm{m}$ (Blazey, 1977; Cloutis et al., 2008). This results in an absorption edge that moves to longer wavelengths with increasing $\mathrm{Fe}^{3+}$ content. The charge transfer band resulting from $\mathrm{Fe}^{3+}-\mathrm{O}$ generally occurs at longer wavelengths than the band resulting from $\mathrm{Fe}^{2+}-\mathrm{O}$ (Cloutis et al., 2008). For low-Ca pyroxenes Cloutis et al. (2008) reported a rapidly decreasing reflectance in the near UV and two broad absorption bands at $\sim 0.22 \mu \mathrm{m}$ and $0.25 \mu \mathrm{m}$. Increasing $\mathrm{Fe}^{2+}$ results in a decrease in overall reflectance and broadening of the absorption bands.

In the MIR, pyroxenes show the characteristic Christiansen feature (CF), Reststrahlen bands, and Transparency features (TF). The reflectance minimum called Christiansen feature occurs at frequency where the absorption coefficient is low and the real part of the index of refraction approaches that of the environment, resulting in the minimum in reflectance and maximum in emission (Christiansen, 1884). The wavelength position of the CF is highly diagnostic in terms of the composition of silicates and silicate-bearing rocks and does not depend on grain size, crystal orientation, and crystallinity (Salisbury and Walter, 1989; Salisbury et al., 1991). While the visible and near-IR spectra of Mg-pyroxenes are rather featureless due to the lack of Fe or other transition elements, fundamental vibrations of $\mathrm{Si}-\mathrm{O}$ bonds in the crystal lattice cause very intense absorption in the mid-IR. Absorption coefficients at the band centers are so high that reflectance is controlled only by surface scattering, producing reflectance maxima called Reststrahlen bands in reflectance spectra (Vincent and Hunt, 1968) and corresponding emissivity minima in emission spectra (Conel, 1969; Lyon, 1964). The positions of Reststrahlen bands in optical spectra of silicates are highly diagnostic since $\mathrm{Si}-\mathrm{O}$ bond strengths and therefore frequencies of Si-O vibrations are strongly affected by adjacent ions and polymerization degree of the silicate framework. In low-Ca orthopyroxenes the Reststrahlen bands are generally located between $8.3 \mu \mathrm{m}$ and $12.5 \mu \mathrm{m}$ and consist of three separate broad maxima with several superposed maxima (Hamilton, 2000; Salisbury et al., 1991). In silicates the TF generally occurs as a broad reflectance maximum between 11 and $13 \mu \mathrm{m}$ (Salisbury, 1993). In this wavelength range, the fine grain size of the fine-grained samples leads to grains becoming optically thin and volume scattering plays a significant role (Salisbury, 1993). Similar to the position of the $\mathrm{CF}$, the wavelength position of the TF is diagnostic of silicates 
and silicate-bearing rocks (Salisbury and Walter, 1989). Mid-IR spectral properties of clinoenstatites have not been studied so far.

\subsection{Polymorphs of enstatite}

Enstatite has four different polymorphs - low clinoenstatite, orthoenstatite, protoenstatite, and high clinoenstatite (Allen et al., 1906; Smyth, 1974). High clinoenstatite is an unstable polymorph. Low clinoenstatite (clinoenstatite hereafter), orthoenstatite, and protoenstatite are stable at low $\left(<700^{\circ} \mathrm{C}\right)$, intermediate $\left(>600^{\circ} \mathrm{C}\right)$, and high $\left(>1000^{\circ} \mathrm{C}\right.$ ) temperatures (Lee and Heuer, 1987). Orthoenstatite (space group $\mathrm{Pbca}$ ) and protoenstatite ( $\mathrm{Pbcn}$ ) are orthorhombic, while clinoenstatite $\left(\mathrm{P} 2{ }_{1} / \mathrm{c}\right)$ is monoclinic. The relative stabilities of the polymorphs are not yet completely understood. Clinoenstatite is formed either by rapid cooling or by shear deformation of proto- or orthoenstatite (Lee and Heuer, 1987). The transformation of proto- and orthoenstatite to clinoenstatite appears to be martensitic in nature (Lee and Heuer, 1987). Protoenstatite does not occur naturally and is unstable at room temperature. The transformation from orthoenstatite to protoenstatite at 1 bar takes place at $985^{\circ} \mathrm{C}$ (Sarver and Hummel, 1962). Upon quenching protoenstatite inverts spontaneously to a mixture of clino- and orthoenstatite (Smyth, 1974). Orthoenstatite is the enstatite polymorph abundant in terrestrial rocks and meteorites like aubrites (Keil, 2010) or enstatite chondrites (Mason, 1966, 1968). Orthoenstatite is also reported to occur on comets (Zolensky et al., 2006). Orthoenstatite occurs in solid solution with ferrosilite and almost FeO-free enstatite is rare in terrestrial rocks (Robinson, 1980). Clinoenstatite is also known from meteorites (Keil, 2010; Mason, 1966, 1968; Reid and Cohen, 1967). Clinoenstatite in enstatite chondrites and aubrites formed presumably by crystallization from a melt and subsequent quenching or mechanical deformation (brecciation) of orthoenstatite (Mason, 1968). Mason (1966) also noted that enstatite chondrites dominated by clinoenstatite are considerably finer grained than the enstatite chondrites dominated by orthoenstatite.

\section{Samples and methods}

\subsection{Synthesis of enstatite}

Synthesis of polycrystalline clinoenstatite and orthoenstatite samples in air yields a sufficient amount of material needed for extended spectroscopic studies but orthoenstatite cannot easily be synthesized at atmospheric pressure. It always inverts to clinoenstatite upon quenching (Boyd and Schairer, 1964). This can be prevented by adding a flux to the clinoenstatite. Sarver and Hummel (1962) synthesized orthoenstatite using LiF-flux. In their experiments clinoenstatite with LiF heated to temperatures between 875 and $940^{\circ} \mathrm{C}$ yielded orthoenstatite. Experiments with temperatures of $870^{\circ} \mathrm{C}$ and lower resulted in clinoenstatite or a mix of orthoenstatite and clinoenstatite. We based our method for the synthesis of orthoenstatite on the method described by Sarver and Hummel (1962).

About $10 \mathrm{~g}$ of pure enstatite was synthesized using reagent-grade chemicals. $\mathrm{SiO}_{2}$ and $\mathrm{MgO}$ powders were dried for at least $12 \mathrm{~h}$ at $100{ }^{\circ} \mathrm{C}$ before usage. Stoichiometric mixtures of the dried powders were thoroughly ground by hand for at least an hour under acetone in an agate mortar to yield a homogeneous mixture. The mixture was filled into a platinum crucible and heated to $1500^{\circ} \mathrm{C}$ for 3 days in a box furnace. After air-quenching, the sample formed a fine powder of clinoenstatite. $\mathrm{X}$-Ray powder diffraction (XRPD) measurements were performed to verify that the oxides have reacted completely and pure clinoenstatite has formed. The clinoenstatite was ground and mixed with $3 \mathrm{wt} \%$ of $\mathrm{LiCl}$ flux. The mixture was again ground by hand for at least $1 \mathrm{~h}$ under acetone in an agate mortar. The ground sample was filled into the platinum crucible and heated for $70 \mathrm{~h}$ to $930^{\circ} \mathrm{C}$. After quenching in air, the sample was only briefly ground, as orthoenstatite can transform to clinoenstatite due to grinding (Lee and Heuer, 1987). The sample was finally measured with XRPD to control if all clinoenstatite had transformed to orthoenstatite.
XRPD measurements were performed using a Philips X'Pert powder diffractometer with $\mathrm{Cu}-\mathrm{K} \alpha$ radiation in Bragg-Brentano parafocusing geometry with a primary monochromator. Measurements were performed from 20 to $55^{\circ}(2 \theta)$ with steps of $0.014^{\circ}$.

The XRPD spectra in Fig. 1 show that both samples are crystalline enstatites. For identification of the samples, synthetic clino- and orthoenstatite from the Powder Diffraction File (PDF) database were used as references. Both samples show the strongest reflections between $25^{\circ}$ and $35^{\circ}$. The strongest reflection in both samples is located at $\sim 31^{\circ}$. The orthoenstatite sample has minor forsterite impurities. Forsterite peaks that do not overlap with orthoenstatite peaks can be seen between $23^{\circ}$ and $26^{\circ}$ and at $\sim 32.5^{\circ} 2 \theta$. We assume that a small amount of $\mathrm{SiO}_{2}$ dissolved in the $\mathrm{LiCl}$-melt lowers the $\mathrm{Si} / \mathrm{Mg}$ of the residue, leading to the formation of minor forsterite.

\subsection{Chemical composition and grain size analysis}

Chemical compositions were measured by JEOL JXA 8900 and JEOL 8530F microprobes equipped with wavelength dispersive X-ray spectrometers at the Institute for Mineralogy at the University Münster. For the analyses the microprobe were operated at $15 \mathrm{kV}$ and $15 \mathrm{nA}$ with a probe diameter of $3 \mu \mathrm{m}$. The compositions of ortho- and clinoenstatite are $\mathrm{En}_{99.9} \mathrm{Fs}_{0.03} \mathrm{Wo}_{0.0}$ and $\mathrm{En}_{99.9} \mathrm{Fs}_{0.05} \mathrm{Wo}_{0.04}$ respectively (Table 1). Despite having detected minor forsterite reflections in the XRPD-measurement of the orthoenstatite sample, we could not detect any forsterite during the chemical characterization. This leads to the assumption that the forsterite occurs as submicroscopic grains.

Along with the enstatites from our own synthesis we also characterized synthetic clinoenstatite, orthoenstatite, and diopside and the aubrite Peña Blanca Spring (PBS). The additional synthetic pyroxenes were synthesized by Robert Housley at the California Institute of Technology between 1965 and 1968. Chemical compositions were measured as for the samples synthesized for this study (Table 1) and yield compositions of $\mathrm{En}_{99.6} \mathrm{Fs}_{0.0} \mathrm{Wo}_{0.4}$ for the orthoenstatite, $\mathrm{En}_{99.7} \mathrm{Fs}_{0.01} \mathrm{Wo}_{0.3}$ for the clinoenstatite, and $\mathrm{En}_{48.8} \mathrm{Fs}_{0.05} \mathrm{Wo}_{51.2}$ for the diopside. Aubrites (enstatite achondrites) in general consist of $74.8-97.5 \mathrm{vol} \%$ of enstatite with an average composition of $\mathrm{En}_{99.0} \mathrm{Fs}_{0.06} \mathrm{Wo}_{0.90}$ (Keil, 2010). Diopsides $(0.2-8.1 \mathrm{vol} \%)$ and forsterites $(0.3-10.0 \mathrm{vol} \%)$ in aubrites are also almost FeO-free (Keil, 2010). This makes aubrites suitable for comparison of the reflectance spectra of our synthetic enstatites with naturally occurring enstatites. Peña Blanca Spring was an observed fall in 1946 with a total weight of $\sim 70 \mathrm{~kg}$ (Keil, 2010; Lonsdale, 1947). Our sample of Peña Blanca Spring consists of enstatite with the composition $\mathrm{En}_{99.4} \mathrm{Fs}_{0.05} \mathrm{Wo}_{0.55}$ making up $\sim 93 \mathrm{vol} \%$ of our sample. The powdered sample of Peña Blanca Spring was sieved to a $<90 \mu \mathrm{m}$ grain size fraction.

Microprobe analyses were averaged over several individual measurements per sample (Table 1). The amount of FeO is very low and the average is below the detection limit of the quantitative analysis in all samples. Single individual measurements yield $\mathrm{FeO}$ of up to $0.09 \mathrm{wt} \%$ in the diopside and $0.05 \mathrm{wt} \%$ in the clinoenstatites.

Grain sizes influence the spectral behavior of samples therefore grain size distributions of all enstatite samples were measured on backscatter electron images of thin sections prepared from the samples (Fig. 2). Diameters of the grains were measured using the ImageJ software (Schneider et al., 2012) and calculated as average from the maximum and minimum Feret's diameter. Diameter distributions are displayed in Fig. 3 and Table 2. In the orthoenstatite sample, $70 \%$ of grains have an average diameter of $<25 \mu \mathrm{m}$. A subsample of the orthoenstatite that was additionally ground has $99 \%$ of grains with an average diameter of $<25 \mu \mathrm{m}$. The clinoenstatite sample has $87 \%$ of grains with an average diameter of $<25 \mu \mathrm{m}$. For Housley's orthoenstatite and clinoenstatite $90 \%$ and $95 \%$ of the grains have average diameters of $<25 \mu \mathrm{m}$. Overall, the orthoenstatite sample is the coarsest sample while the additionally ground orthoenstatite is the finest grained sample (Fig. 2). The orthoenstatite sample shows significantly more grains with grain sizes $>32 \mu \mathrm{m}$ than the other samples. In the additionally ground orthoenstatite 


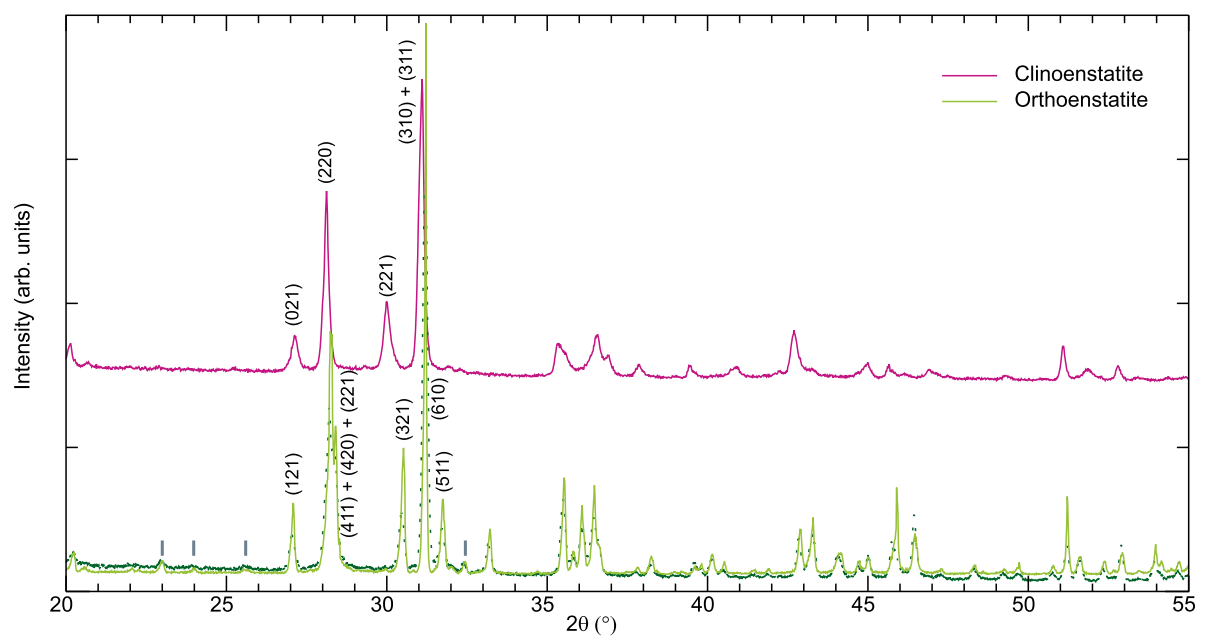

Fig. 1. XRPD spectra of enstatites. Spectra are offset for clarity. The clinoenstatite spectrum was recorded with a linear position sensitive detector (PSD), the orthoenstatite spectrum with a proportional detector. Additionally, an orthoenstatite spectrum recorded with a PSD is shown as a dotted line. Some minor peaks of forsterite in the orthoenstatite spectrum that do not overlap with orthoenstatite peaks are marked with gray dashes.

Table 1

Chemical compositions of synthetic pyroxenes and enstatite in Peña Blanca Spring (PBS) in wt\%. Composition of enstatite En $\mathrm{n}_{100}$ (sample 001) taken from Klima et al. (2007). $\mathrm{n}$ gives the number of individual analyses.

\begin{tabular}{|c|c|c|c|c|c|c|c|}
\hline & $\begin{array}{l}\text { Orthoenstatite } \\
\text { (this study) }\end{array}$ & $\begin{array}{l}\text { Clinoenstatite } \\
\text { (this study) }\end{array}$ & $\begin{array}{l}\text { Orthoenstatite } \\
\text { (Housley) }\end{array}$ & $\begin{array}{l}\text { Clinoenstatite } \\
\text { (Housley) }\end{array}$ & $\begin{array}{l}\text { Diopside } \\
\text { (Housley) }\end{array}$ & $\begin{array}{l}\text { Enstatite } \\
\text { (PBS) }\end{array}$ & $\begin{array}{l}\mathrm{En}_{100} \\
\text { (Klima) }\end{array}$ \\
\hline $\mathrm{n}$ & 5 & 7 & 2 & 10 & 5 & 4 & - \\
\hline $\mathrm{SiO}_{2}$ & $59.73 \pm 0.28$ & $59.12 \pm 0.32$ & $59.29 \pm 0.22$ & $60.09 \pm 0.56$ & $55.66 \pm 2.76$ & $59.64 \pm 1.34$ & 59.86 \\
\hline $\mathrm{TiO}_{2}$ & $0.03 \pm 0.04^{\mathrm{b}}$ & $0.02 \pm 0.04^{\mathrm{b}}$ & n.d. & $0.03 \pm 0.04^{\mathrm{b}}$ & $0.03 \pm 0.00^{\mathrm{b}}$ & $0.04 \pm 0.02$ & - \\
\hline $\mathrm{Al}_{2} \mathrm{O}_{3}$ & $0.18 \pm 0.26$ & $0.16 \pm 0.06$ & $0.10 \pm 0.04$ & $0.02 \pm 0.02^{\mathrm{b}}$ & $0.05 \pm 0.12$ & $0.09 \pm 0.08$ & 0.06 \\
\hline $\mathrm{FeO}^{\mathrm{a}}$ & $0.03 \pm 0.04^{\mathrm{b}}$ & $0.03 \pm 0.02^{\mathrm{b}}$ & n.d. & $0.02 \pm 0.04^{\mathrm{b}}$ & $0.05 \pm 0.06$ & $0.03 \pm 0.02^{\mathrm{b}}$ & 0.06 \\
\hline $\mathrm{MnO}$ & $0.03 \pm 0.00^{\mathrm{b}}$ & $0.02 \pm 0.02^{\mathrm{b}}$ & n.d. & $0.01 \pm 0.02^{\mathrm{b}}$ & $0.01 \pm 0.00^{\mathrm{b}}$ & $0.06 \pm 0.1$ & n.d. \\
\hline $\mathrm{MgO}$ & $39.34 \pm 0.72$ & $39.33 \pm 0.26$ & $39.45 \pm 0.44$ & $39.52 \pm 0.32$ & $17.76 \pm 4.3$ & $38.52 \pm 1.00$ & 39.75 \\
\hline $\mathrm{Cr}_{2} \mathrm{O}_{3}$ & $0.02 \pm 0.02^{\mathrm{b}}$ & $0.02 \pm 0.02^{\mathrm{b}}$ & n.d. & $0.02 \pm 0.04^{\mathrm{b}}$ & $0.03 \pm 0.04^{\mathrm{b}}$ & $0.06 \pm 0.04$ & - \\
\hline $\mathrm{CaO}$ & $0.03 \pm 0.04^{\mathrm{b}}$ & $0.03 \pm 0.02^{\mathrm{b}}$ & $0.23 \pm 0.06^{\mathrm{b}}$ & $0.18 \pm 0.04$ & $25.99 \pm 0.9$ & $0.31 \pm 0.40^{\mathrm{b}}$ & 0.03 \\
\hline $\mathrm{Na}_{2} \mathrm{O}$ & $0.02 \pm 0.02^{\mathrm{b}}$ & $0.02 \pm 0.04^{\mathrm{b}}$ & n.d. & $0.01 \pm 0.02^{\mathrm{b}}$ & $0.06 \pm 0.18^{\mathrm{b}}$ & $0.04 \pm 0.04^{\mathrm{b}}$ & - \\
\hline $\mathrm{K}_{2} \mathrm{O}$ & n.d. & $0.01 \pm 0.02^{\mathrm{b}}$ & $0.03 \pm 0.06^{\mathrm{b}}$ & $0.01 \pm 0.02^{\mathrm{b}}$ & $0.03 \pm 0.00^{\mathrm{b}}$ & $0.01 \pm 0.00^{\mathrm{b}}$ & - \\
\hline Total & $99.41 \pm 0.24$ & $98.76 \pm 0.28$ & $99.12 \pm 0.38$ & $99.91 \pm 0.76$ & $99.64 \pm 0.94$ & $98.80 \pm 0.62$ & 99.76 \\
\hline
\end{tabular}

${ }^{\mathrm{a}}$ All Fe is reported as FeO. ${ }^{\mathrm{b}}$ Below detection limit. n.d. $=$ not detected.
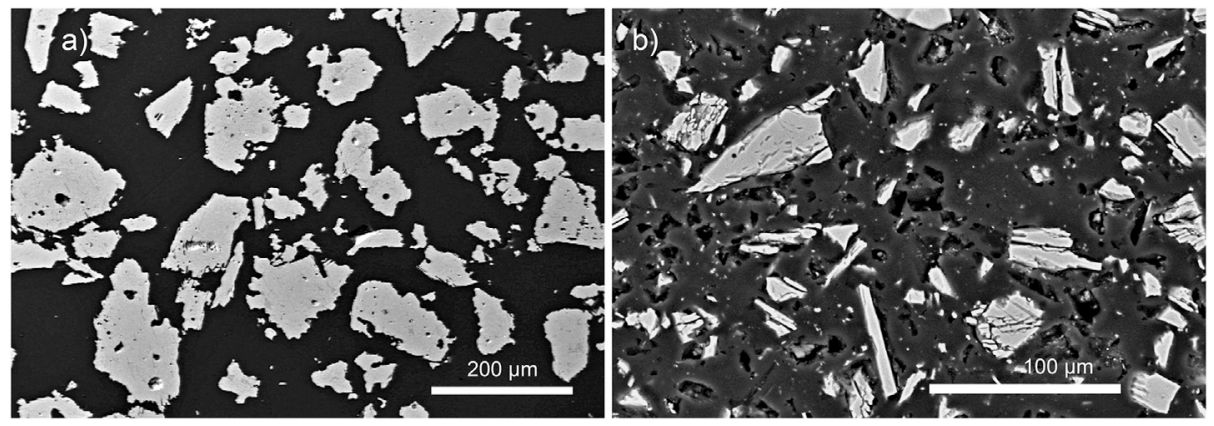

Fig. 2. Backscattered electron images of (a) the original orthoenstatite sample and (b) the additionally ground orthoenstatite sample (light grey) mounted in epoxy resin (dark grey).

the abundance of grains in the $<5 \mu \mathrm{m}$ grain size fraction is more than twice higher than in the original orthoenstatite sample. Housley's clinoenstatite has a higher percentage of grains in the $<25 \mu \mathrm{m}$ grain size fraction but a lower percentage in the $<5 \mu \mathrm{m}$ grain size fraction than our clinoenstatite and Housley's orthoenstatite. Housley's clinoenstatite has higher percentages of grains in the 5-10 $\mu \mathrm{m}, 10-15 \mu \mathrm{m}, 15-20 \mu \mathrm{m}$, and $20-25 \mu \mathrm{m}$ than our clinoenstatite and Housley's orthoenstatite. It has to be noted that the measured diameters are smaller than the true diameters of the grains, because of the thin sections cutting grains randomly and not necessarily at their largest extent.

The synthesis using loose powders has led to internal porosity within both samples. Cavities and holes in the clinoenstatite sample make up $3.30 \mathrm{vol} \%$ of the entire sample. The porosity in the orthoenstatite sample is lower with $1.98 \mathrm{vol} \%$. Reheating the clinoenstatite together with the flux has probably resulted in the decreased porosity of the orthoenstatite sample.

\subsection{Spectral measurements}

We collected $0.25-17 \mu \mathrm{m}$ biconical reflectance spectra of all samples under vacuum using the Bruker Vertex 80v FTIR-spectrometer at the Planetary Spectroscopy Laboratory (PSL) of the Institute of Planetary 

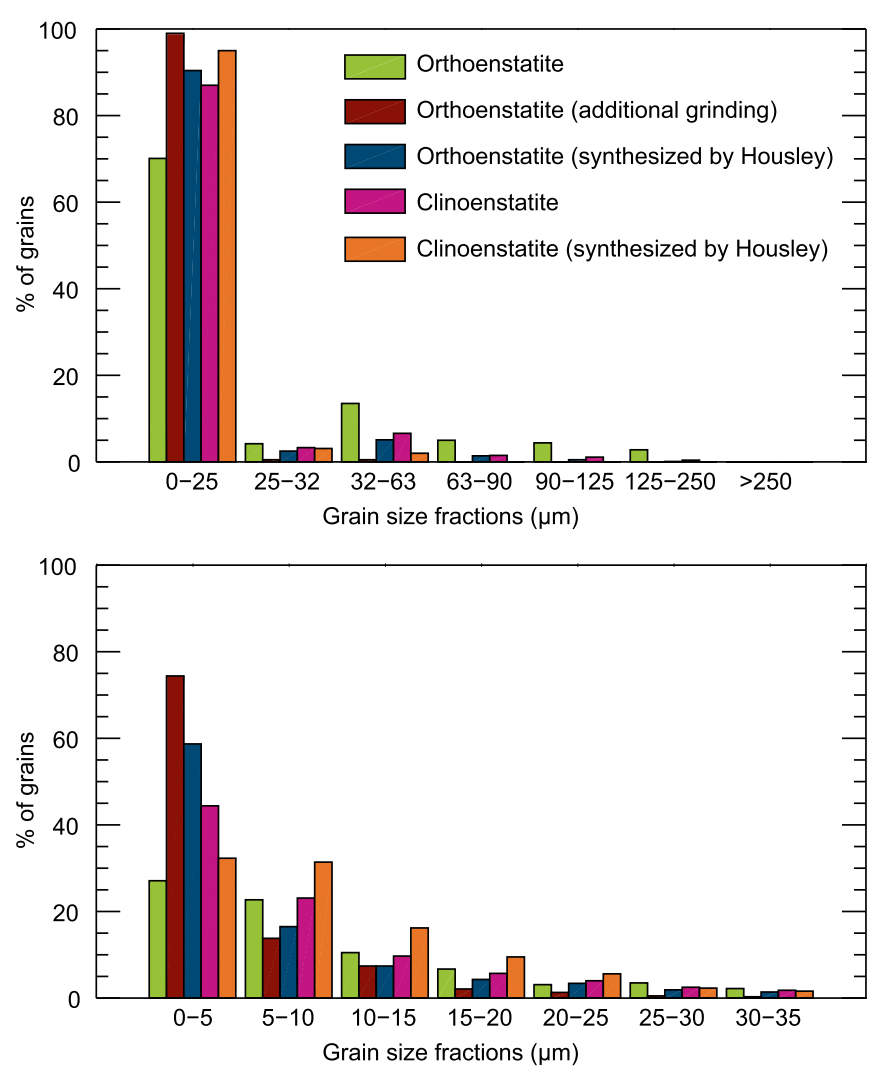

Fig. 3. Grain size distributions for the orthoenstatite and clinoenstatite samples. Upper panel: Grain size distributions binned to common sieving grain sizes. Lower panel: Grain size distributions of smaller grain sizes binned to $5 \mu \mathrm{m}$ steps.

Table 2

Average, mode, and median diameters in $\mu \mathrm{m}$ of the enstatite samples.

\begin{tabular}{llll}
\hline & Average & Mode & Median \\
\hline Orthoenstatite & 26 & 3 & 10 \\
Orthoenstatite (additional grinding) & 4 & 1 & 2 \\
Clinoenstatite & 13 & 3 & 6 \\
Clinoenstatite Housley & 10 & 3 & 8 \\
Orthoenstatite Housley & 10 & 2 & 4 \\
\hline
\end{tabular}

Research at DLR, Berlin. For all measurements, a Bruker A513 reflectance unit with incidence and emergence angles both set to $15^{\circ}$ with a resulting phase angle of $30^{\circ}$ was used. The composite spectrum for each sample is merged from several individual measurements at different wavelength ranges. Spectral resolution ranges from $50 \mathrm{~cm}^{-1}$ at the shortest wavelength to $4 \mathrm{~cm}^{-1}$ at the longest wavelength. To cover the entire spectral range of $0.25-17 \mu \mathrm{m}$, different detectors (GaP-diode, Si-diode, MCT detector, and additionally for the orthoenstatite InGaAs detector), beamsplitters $\left(\mathrm{CaF}_{2}, \mathrm{Si}\right.$ on $\mathrm{CaF}_{2}$, and $\mathrm{KBr}$ broadband), and different sources (deuterium source, tungsten lamp, globar) were used. The measurements were performed relative to a calibration standard. $\mathrm{BaSO}_{4}$, spectralon, and a diffuse gold standard were used depending on the spectral range. All spectra were averaged over at least 500 individual scans.

\section{Results and discussion}

\subsection{UV-VIS-NIR spectroscopy}

Reflectance spectra of orthoenstatites and clinoenstatites between $0.25 \mu \mathrm{m}$ and $4.5 \mu \mathrm{m}$ are displayed in Fig. 4. Spectral slopes in the VIS and NIR are almost neutral (flat) with the clinoenstatite and Housley's orthoentstatite showing slightly bluish (negative) trends. All spectra show steep red slopes in the near UV. The slope in the UV is steeper in both orthoenstatite samples than in the clinoenstatites (Fig. 5). Slopes in the orthoenstatites are similar to each other. The same is true for the two clinoenstatites. The wavelengths of slope change, determined as the wavelength of the intersection of two linear slopes fitted in the UV and VIS, for our orthoenstatite and Housley's orthoenstatite are $0.36 \mu \mathrm{m}$ and $0.35 \mu \mathrm{m}$, respectively. For our clinoenstatite and Housley's clinoenstatite the wavelengths of slope change are $0.43 \mu \mathrm{m}$ and $0.38 \mu \mathrm{m}$, respectively. In both orthoenstatite samples, the position of the wavelength of slope change (absorption edge) is located at shorter wavelengths than in the clinoenstatites. These slopes are long-wavelength wings of intense oxygen-to-metal charge-transfer (OMCT) absorption bands centered between $0.2 \mu \mathrm{m}$ and $0.3 \mu \mathrm{m}$ (Burns, 1993a; b; Cloutis et al., 2008). The UV slopes are caused by intense metal-O charge transfer absorptions. In general, the absorption edge moves to longer wavelengths with increasing Fe content in Fe-bearing minerals (Cloutis et al., 2008). The positions of the wavelength of slope change suggest that the enstatites synthesized for this study contain more Fe than Housley's enstatites. This is also consistent with the fact that the UV-absorption bands in reflectance spectra of orthoenstatite and clinoenstatite synthesized in this study are deeper than in the spectra of Housley's ortho- and clinoenstatite. However, some factors other than Fe-content can contribute to the position of the UV-absorption edge including the presence of other cations of the first transition series (e.g., Ti, Mn, Cr ions) that can contribute to the UV OMCT absorption. An additional factor could be relative abundances of ferric and ferrous ions in the samples. The $\mathrm{Fe}^{3+}-\mathrm{O}$ charge transfer bands in the UV are generally two orders of magnitudes stronger than the $\mathrm{Fe}^{2+}-\mathrm{O}$ absorption (Cloutis et al., 2008). The absorption edge of the $\mathrm{Fe}^{3+}-\mathrm{O}$ charge transfer band is generally located at longer wavelength than the absorption edge of the $\mathrm{Fe}^{2+}-\mathrm{O}$ charge transfer band (Cloutis et al., 2008). The differences in the UV slope might be caused by more $\mathrm{Fe}^{3+}$ being present in the orthoenstatites. This would concur with the oxidation of $\mathrm{Fe}^{2+}$ during the reheating step in the synthesis of the orthoenstatite. However, the positions of the absorption edge do not support this conclusion and the procedures of synthesis used by R. Housley are not known to us.

Grain size distribution is an additional factor that can affect the position of the UV absorption edge and the near-UV spectral slopes (e.g., Cloutis et al., 2008; Mustard and Hays, 1997). Grain size variations influence widths and depths of UV absorption bands in the spectra of powdered minerals (Cloutis et al., 2008). This can contribute to the observed spectral differences between our samples. In particular, the differences in the positions of the UV absorption edges and the depths of UV features between our and Housley's samples can be explained by variations in grain sized distributions described in Section 2.2. Our orthoenstatite is significantly coarser-grained and less porous compared to Housley's orthoenstatite, which can explain its deeper UV absorption and the longer wavelength position of the UV absorption edge. The same concerns the observed spectral differences between the two clinoenstatites. However, the observed spectral differences between synthetic ortho- and clinoenstatites are difficult to attribute to grain size variations and are more likely related to composition (contents of different ions of transition elements) or structure. All transition elements that may contribute to the UV absorptions are present in trace amounts which are below the detection limits of the electron microprobe analysis (Table 1) making it impossible to conclusively attribute the relatively "wide" UV bands in reflectance spectra of synthetic clinoenstatites to the higher abundances of specific ions. It is also possible that synthetic clinoenstatites show more variance in the metal-oxygen bond length and are structurally somewhat more disordered than synthetic orthoenstatites, which could explain the wider and generally weaker UV absorption features in the clinoenstatite spectra compared to the orthoenstatite ones.

Both clinoenstatite samples show weak absorption features due to iron ions in the VIS and NIR. The clinoenstatite produced in this study shows absorption bands at approximately $0.9 \mu \mathrm{m}$ and $1.8 \mu \mathrm{m}$. Both absorption bands can be attributed to $\mathrm{Fe}^{2+}$ in $\mathrm{M} 2$ positions of the 


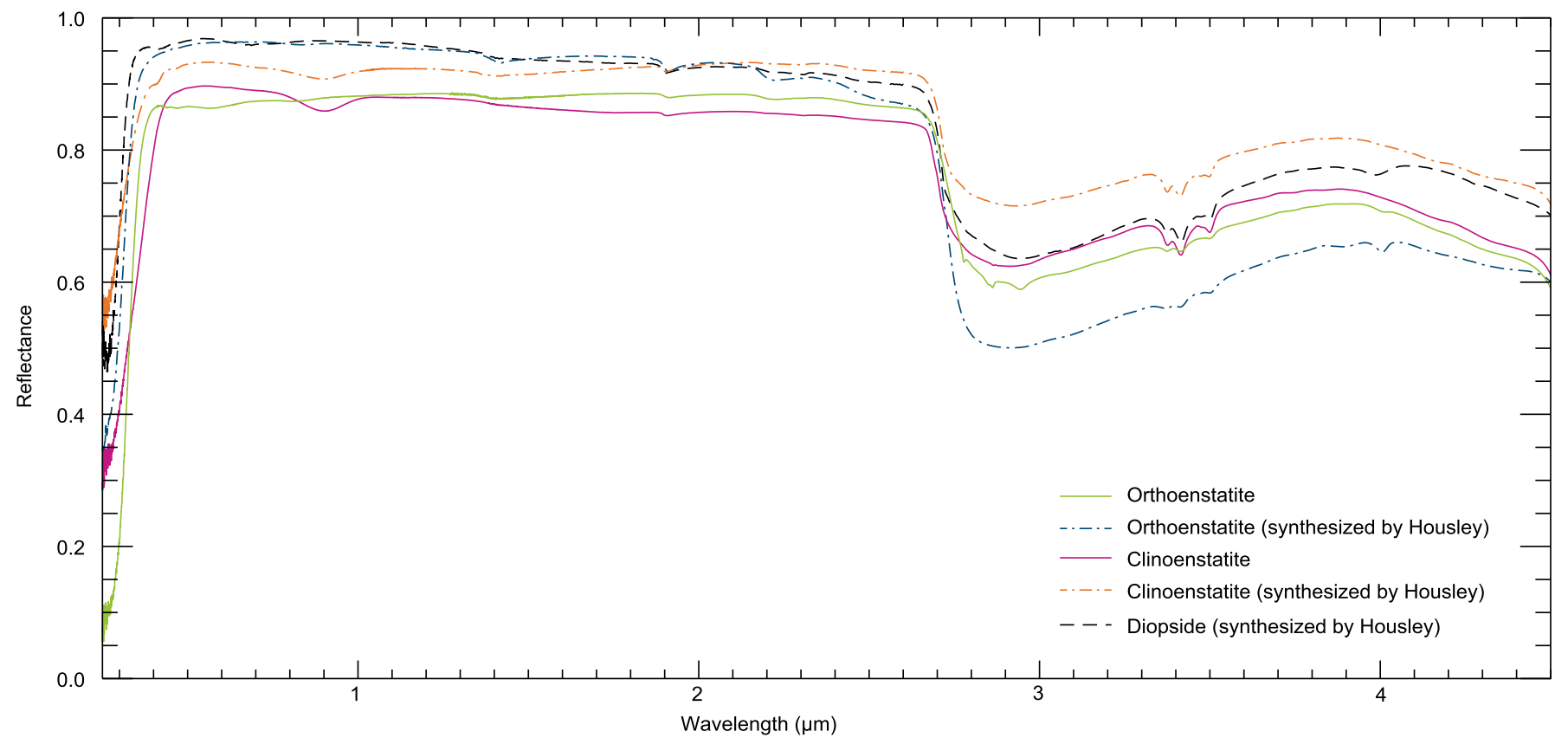

Fig. 4. Reflectance spectra of synthetic orthoenstatites and clinoenstatites from 0.25 to $4.5 \mu \mathrm{m}$. Reflectance spectrum of synthetic diopside is shown for comparison.

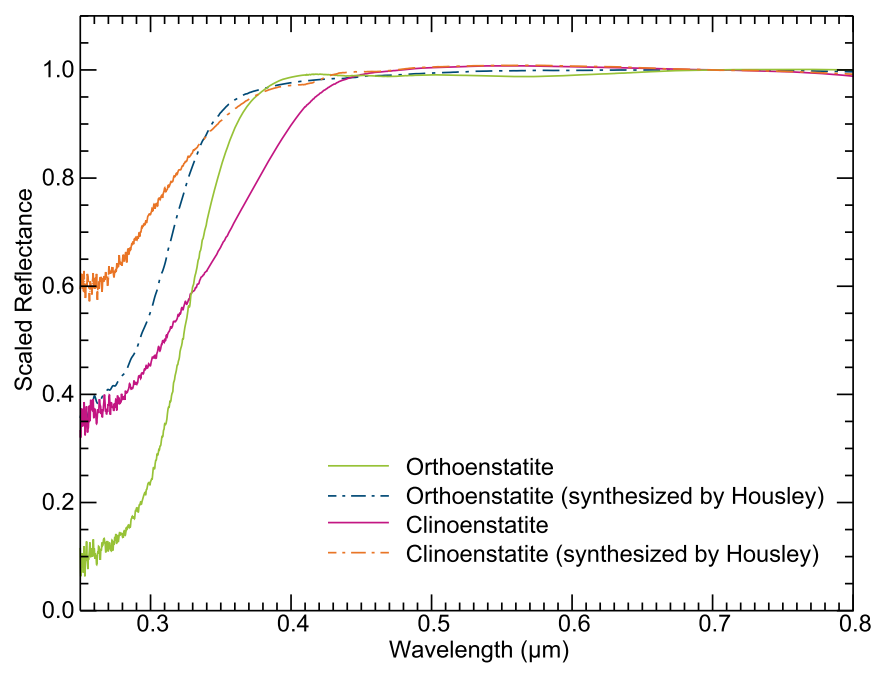

Fig. 5. Reflectance spectra of the ortho- and clinoenstatite scaled to unity at $0.7 \mu \mathrm{m}$. The UV slopes in the spectra of the orthoenstatites are significantly steeper than the slopes in the spectra of clinoenstatites. The absorption edges in the orthoenstatite spectra are located at shorter wavelengths than in the clinoenstatite spectra. The wavelengths of slope change for the orthoenstatite and Housley's orthoenstatite are $0.36 \mu \mathrm{m}$ and $0.35 \mu \mathrm{m}$, respectively. For the clinoenstatite and Housley's clinoenstatite the wavelengths of slope change are $0.43 \mu \mathrm{m}$ and $0.38 \mu \mathrm{m}$.

clinoenstatite. Housley's clinoenstatite shows a weak absorption band at $\sim 0.9 \mu \mathrm{m}$. The $0.9 \mu \mathrm{m}$ absorption bands in both samples are modeled using the modified Gaussian model (MGM) of Sunshine et al. (1990). Using the MGM, the spectra are described as a continuum with superposed absorptions of the electronic transition absorption bands. The MGM describes the individual absorption bands with modified Gaussian distributions using the following parameters: band center, width, and strength. The resulting parameters for the clinoenstatite spectra are listed in Table 3. Both clinoenstatites show the absorption band at exactly the same wavelength and a similar width but the absorption feature in our clinoenstatite is deeper than in Housley's clinoenstatite. This could be an effect of grain size and/or $\mathrm{Fe}^{2+}$ content of the sample. The average grain
Table 3

Final fitting parameters of the MGM fit for $0.9 \mu \mathrm{m}$ absorption in the clinoenstatites.

\begin{tabular}{llll}
\hline & Center & FWHM & Strength \\
\hline Clinoenstatite & 0.896 & 0.156 & $-2.941 \mathrm{E}-02$ \\
Clinoenstatite (Housley) & 0.896 & 0.159 & $-2.146 \mathrm{E}-02$ \\
\hline
\end{tabular}

size of Housley's clinoenstatite is smaller than the clinoenstatite synthesized for this study but the percentage of grains smaller than $5 \mu \mathrm{m}$ is larger in our clinoenstatite sample than in Housley's clinoenstatite. Housley's clinoenstatite has a higher percentage of grains in the 5-10 $\mu \mathrm{m}$, $10-15 \mu \mathrm{m}$, and $15-20 \mu \mathrm{m}$ grain size ranges. Mustard and Hays (1997) have observed decreasing depths of absorption bands in NIR in a very fine-grained olivine. The higher amount of grains with diameters $<25 \mu \mathrm{m}$ in Housley's clinoenstatite could lead to the reduced depth of the absorption band compared to our clinoenstatite. FeO content in both clinoenstatites are below the detection limit of the microprobe but different amounts of $\mathrm{Fe}^{2+}$ would also influence the depths of the absorption band.

The reflectance spectrum of orthopyroxene produced in this study shows several overlapping weaker absorption bands centered at 0.44 , 0.47, 0.57, and $0.82 \mu \mathrm{m}$ (Fig. 6). It has been shown by Straub et al. (1991) that heating enstatite in air results in nanometer-sized hematite coating the enstatite grains due to oxidation of the $\mathrm{Fe}^{2+}$ to $\mathrm{Fe}^{3+}$. Even though most of the $\mathrm{Fe}^{2+}$ remains unoxidized in the crystal structure of the enstatite, the hematite masks the enstatite's spectral features (Straub et al., 1991). Hematite shows strong absorption features in the wavelength range between 0.4 and $0.9 \mu \mathrm{m}$ (e.g., Morris et al., 1985). However, a direct comparison with our spectra is difficult due to the saturated character of these bands and strong OMCT absorption evident in pure nanophase hematite spectra. Reflectance spectra of small amounts of nanophase hematite $\left(0.2 \mathrm{wt} \% \mathrm{Fe}_{2} \mathrm{O}_{3}\right)$ dispersed in transparent silica gel matrix show only a single $0.45-\mu \mathrm{m}$ weak absorption due to electronic transition of $\mathrm{Fe}^{3+}$ as an inflection on a wing of the OMCT absorption whose absorption edge is located at $\sim 0.6 \mu \mathrm{m}$ (Morris and Lauer, 1990). Thus, the variety of weak bands in the spectrum of our orthoenstatite is unlikely to be attributed to the formation of nanophase hematite during the synthesis. Traces of chlorite (see below) might also produce a series of absorption bands related to $\mathrm{Fe}^{3+}$ transitions and $\mathrm{Fe}^{2+}-\mathrm{Fe}^{3+}$ charge transfer but the positions of these bands in chlorite reflectance spectra 


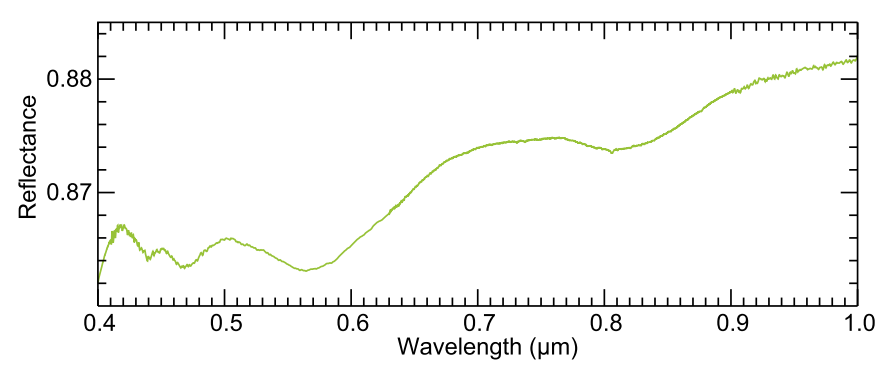

Fig. 6. Absorption bands in the orthoenstatite spectrum between 0.4 and $1 \mu \mathrm{m}$.

(e.g., Bishop et al., 2008) do not correspond to those observed in our orthoenstatite spectrum. It is therefore more likely that the weak features in our orthoenstatite spectrum are caused by crystal field transitions (and possibly charge transfers) in Fe ions and other ions of transition elements (like $\mathrm{Cr}, \mathrm{Mn}, \mathrm{Ti}$ ) incorporated into the pyroxene structure (Cloutis, 2002; Klima et al., 2007 and references therein). These ions are present in trace amounts which are below the detection limits of the electron microprobe analysis (Table 1). The exact assignments are, however, uncertain. For example, $\mathrm{Mn}^{3+}, \mathrm{Fe}^{2+}, \mathrm{Cr}^{3+}$ crystal field transitions might contribute to the broad weak band centered at $0.57 \mu \mathrm{m}$ (Cloutis, 2002; Klima et al., 2007). The overlapping bands centered at 0.44 and $0.47 \mu \mathrm{m}$ might be attributed to transitions and charge transfers involving $\mathrm{Fe}^{2+}, \mathrm{Cr}^{3+}, \mathrm{Ti}^{3+}$, $\mathrm{Ti}^{4+}$ with possible contribution from $\mathrm{Fe}^{3+}$ in nanophase hematite if present. The spin-forbidden band at $0.505 \mu \mathrm{m}$, typical for low-Ca pyroxenes (e.g., Klima et al., 2007), was not observed in our spectra. The absorption band near $0.82 \mu \mathrm{m}$ is likely due to $\mathrm{Fe}^{2+}-\mathrm{Fe}^{3+}$ intervalence charge transfer (IVCT)(e.g., Burns, 1993a).

Housley's clinoenstatite also shows two weak absorption features between 0.4 and $0.5 \mu \mathrm{m}$ (at 0.41 and $0.465 \mu \mathrm{m}$ ) (Figs. 4 and 5). The 0.41$\mu \mathrm{m}$ band could be attributed to $\mathrm{Mn}^{3+}$ and/or $\mathrm{Fe}^{2+}$ crystal field transitions, while a wide variety of ions $\left(\mathrm{Fe}^{2+}, \mathrm{Cr}^{3+}, \mathrm{Ti}^{3+}, \mathrm{Ti}^{4+}\right)$ might contribute to the $0.465-\mu \mathrm{m}$ feature (Cloutis, 2002; Klima et al., 2007 and references therein). It should be noted that formation of some ions like $\mathrm{Fe}^{2+}, \mathrm{Cr}^{3+}, \mathrm{Ti}^{3+}$ during the pyroxene synthesis in air is rather unlikely, however we observe detectable $\mathrm{Fe}^{2+}$ absorption bands near $\sim 0.9 \mu \mathrm{m}$ in reflectance spectra of both clinoenstatite samples (Fig. 4). Therefore, we cannot exclude contribution of trace amounts of $\mathrm{Cr}^{3+}, \mathrm{Ti}^{3+}$ to the spectral features described above.

In addition, weak absorption bands arising from combinations of $\mathrm{OH}-$ stretch and $\mathrm{H}-\mathrm{O}-\mathrm{H}$ bend are located at $1.9 \mu \mathrm{m}$ in all spectra. Another absorption at $1.4 \mu \mathrm{m}$ in all spectra results from the 1 st overtone of the $\mathrm{O}$ $\mathrm{H}$ stretch. Absorption bands due to combination of $\mathrm{O}-\mathrm{H}$ stretches and metal-O-H bends are located at $2.2 \mu \mathrm{m}$ in the orthoenstatites and at $2.2 \mu \mathrm{m}$ and $2.3 \mu \mathrm{m}$ in the clinoenstatites. The presence of the metal-OH combinations in the spectra suggests trace amounts of phyllosilicates in the synthetic samples (Clark et al., 1990). At wavelengths around $3 \mu \mathrm{m}$ all samples show a broad and very intense absorption band due to $\mathrm{O}-\mathrm{H}$ stretches in adsorbed and structural water. In the spectrum of our synthetic orthopyroxene, some fine structure with additional minima near $\sim 2.78, \sim 2.86$, and $2.94 \mu \mathrm{m}$ due to $\mathrm{O}-\mathrm{H}$ stretches in hydroxyl groups is observed. Positions of the individual minima are consistent with those of O-H stretches in chlorite group minerals (e.g., Bishop et al., 2008). The surface contamination of pyroxene grains by trace amounts of OH-bearing phyllosilicates is consistent with the pyroxene synthesis performed in air, while formation of $\mathrm{OH}$ groups directly incorporated into the structure of our synthetic pyroxenes is unlikely. Finally, a series of overlapping absorption bands resulting from symmetric and antisymmetric C-H stretches in methyl and methylene groups are evident at $\sim 3.35$ and $3.5 \mu \mathrm{m}$. The latter features are due to minor organic contamination. The deeper hydrocarbon $\mathrm{C}-\mathrm{H}$ features in the clinoenstatite spectra compared to the orthoenstatite spectra suggest that the clinoenstatite samples are more contaminated with organics then the orthoenstatite powders used in this study.
Even though our laboratory spectra show features indicating minor contamination by $\mathrm{OH}, \mathrm{H}_{2} \mathrm{O}$, and organics, they do not influence the identification of Fe-free silicates.

Both orthoenstatite spectra show a weak absorption band at $4.0 \mu \mathrm{m}$ of unclear origin. The absorption band is slightly stronger in the spectrum of the orthoenstatite synthesized by Housley than in the spectrum of the orthoenstatite synthesized for this study.

Comparing the spectra of the two enstatites synthesized for this study with an ortho- and clinoenstatite synthesized and provided by R. Housley show very similar spectral characteristics. Some minor differences are observable in the VIS and NIR in terms of overall reflectance but this is also controlled by grain size distributions of the samples, and minor absorption bands due to $\mathrm{Fe}^{2+}$ and/or $\mathrm{Fe}^{3+}$.

The synthetic diopside shows very similar spectral behavior in the VIS and NIR (Fig. 4). The steep red slope in the UV is similar to the slopes of both orthoenstatites. The absorption edge is located at considerably shorter wavelengths with the wavelength of slope change located at $0.33 \mu \mathrm{m}$. The spectrum shows a slightly bluish slope throughout the VNIR with some weak absorptions features between 0.4 and $1 \mu \mathrm{m}$. Similarly to the enstatite spectra, absorptions bands at $1.4 \mu \mathrm{m}, 1.9 \mu \mathrm{m}, 2.2 \mu \mathrm{m}$, $2.3 \mu \mathrm{m}$, and between $\sim 3.35$ and $3.5 \mu \mathrm{m}$ and a broad absorption band around $3 \mu \mathrm{m}$ are visible. Similarly to the $4.0 \mu \mathrm{m}$ band in the orthoenstatites spectra, an absorption band is visible in the diopside spectrum at a slightly shorter wavelength of $3.99 \mu \mathrm{m}$.

\subsection{MIR spectroscopy}

MIR reflectance spectra of both ortho- and clinoenstatites are displayed in Figs. 7 and 8. The reflectance spectrum of Housley's synthetic diopside powder is shown for comparison. At wavelengths between 4.5 and $7.1 \mu \mathrm{m}$ some weak absorption bands are visible primarily due to combination tones of the fundamental molecular vibration bands with lattice modes (Salisbury, 1993). Between 4.5 and $8 \mu \mathrm{m}$ the reflectance spectra of orthoenstatite, clinoenstatite, and Housley's clinoenstatite are almost identical except for overall brightness. In the Housley orthoenstatite spectrum an additional absorption band appears at $6.47 \mu \mathrm{m}$, while the $\sim 7 \mu \mathrm{m}$ absorption feature is deeper and wider. Housley's orthoenstatite contains some impurities of quartz and other $\mathrm{Ca}, \mathrm{Fe}, \mathrm{Mg}$-rich silicates in the center of orthoenstatite grains which could be the cause for these differences. All synthetic enstatite spectra can be easily distinguished from the spectrum of Housley's synthetic diopside (as well as other diopsides, see, e.g., Moroz et al., 1996) in this spectral range. For example, the spectra of diopsides show distinct reflectance maximum near $5.6 \mu \mathrm{m}$ and some absorption bands (e.g., at $5.07 \mu \mathrm{m}$ ) that are absent in enstatite reflectance spectra. Our results demonstrate that although the spectral range between 4.5 and $7.5 \mu \mathrm{m}$ has limited usefulness in remote sensing applications, it has certain diagnostic potential in laboratory reflectance spectroscopy of Fe-free or Fe-poor pyroxene-rich assemblages. Although one cannot distinguish between monoclinic and orthorhombic enstatites in this spectral range, one can easily detect the spectral differences between low-Ca and high-Ca content Fe-free pyroxenes, which is impossible in the UV-NIR spectral region because of the lack of Fe ions in the pyroxene structure.

The Christiansen feature in reflectance spectra of all enstatite samples is located at $8.35 \mu \mathrm{m}$. In the spectral region of Reststrahlen bands between 8.5 and $12 \mu \mathrm{m}$, the two enstatite sample groups show some differences. The Reststrahlen bands of low-Ca pyroxenes generally consist of three major reflectance maxima. Our results demonstrate that the fine structures of the Reststrahlen bands are more pronounced in the orthoenstatite spectra than in clinoenstatite spectra. Both sample groups of ortho- and clinoenstatites show mostly the same structures in the Reststrahlen bands with small differences. The three major reflectance maxima each consisting of several overlapping peaks are located at $\sim 9 \mu \mathrm{m}, \sim 10.5 \mu \mathrm{m}$, and $\sim 11.6 \mu \mathrm{m}$. The orthoenstatite synthesized for this study, the orthoenstatite synthesized by Housley, the enstatite $\mathrm{En}_{100}$ from Klima et al. (2007), and Peña Blanca Spring show the same fine structure 


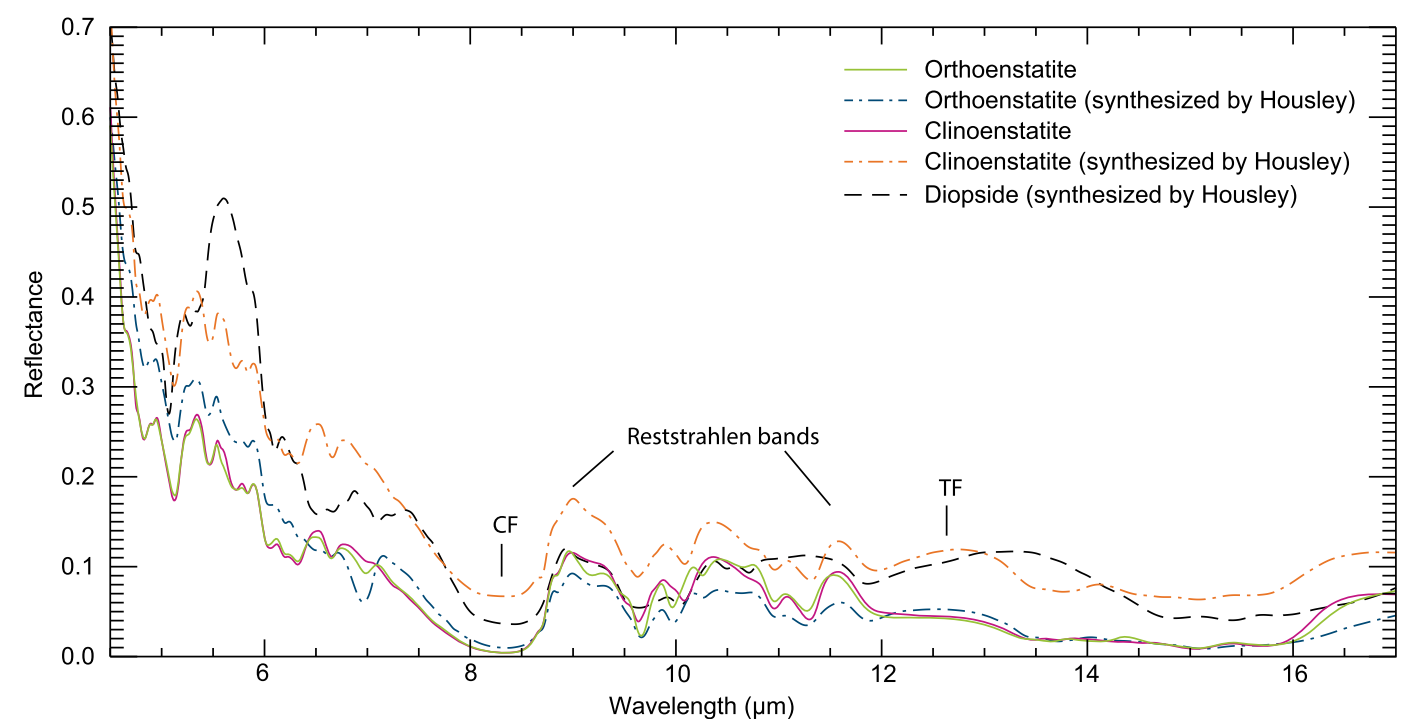

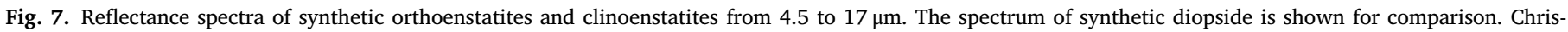
tiansen feature (CF), Reststrahlen bands, and transparency feature (TF) are indicated.

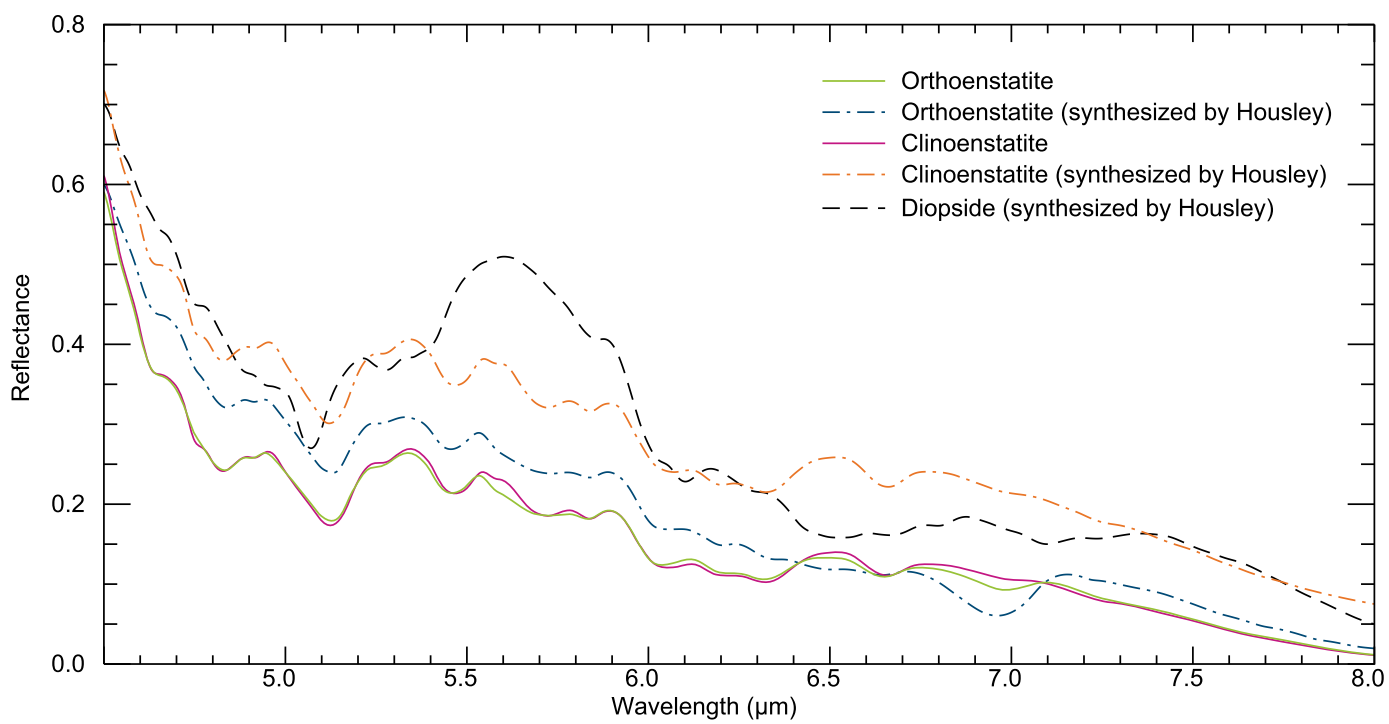

Fig. 8. Reflectance spectra of synthetic orthoenstatites and clinoenstatites from 4.5 to $8 \mu \mathrm{m}$. The spectrum of synthetic diopside is shown for comparison.

within the Reststrahlen bands (Fig. 9). Klima et al. (2007) reported to have only used orthopyroxenes for their study. The reflectance spectra of two clinoenstatite samples also show the same fine structure, which is different from the structure observed in the spectra of orthoenstatites. The orthoenstatite spectra show an additional minimum and positions for one minimum are shifted between the ortho- and clinoenstatite spectra (Fig. 9). The orthoenstatite spectra show local minima at $9.96 \mu \mathrm{m}$ and at $10.26 \mu \mathrm{m}$, while the clinoenstatite spectra show a single minimum at $10.09 \mu \mathrm{m}$. Additionally, the minimum between 9.6 and $9.7 \mu \mathrm{m}$ is shifted between the clino- and orthoenstatites. It is located at $9.63 \mu \mathrm{m}$ in the clinoenstatites and at $9.67 \mu \mathrm{m}$ in the orthoenstatites. As a result, the peak at $\sim 9.9 \mu \mathrm{m}$ is broader in the clinoenstatite spectrum while the peak in the orthoenstatite spectrum is narrower. For comparison, the synthetic diopside provided by R. Housley shows the same characteristics as the clinoenstatites in this spectral range. The different minima positions and number of peaks in this spectral range but also the width of the peak at $\sim 9.9 \mu \mathrm{m}$ seem to be diagnostic to discriminate between clino- and orthopyroxenes and based solely on structural differences in the arrangement of the $\mathrm{SiO}_{4}$ tetrahedra. Futhermore, the diopside spectrum is clearly different from all enstatite spectra in the range between 10.7 and $11.7 \mu \mathrm{m}$, where it shows a single broad Reststrahlen band (reflectance maximum), unlike all enstatite spectra that show narrow reflectance maxima at 11.07 and $11.57 \mu \mathrm{m}$ with local minima at 10.96 and $11.3 \mu \mathrm{m}$ (Fig. 9). The same differences in this spectral range are observed between the spectra of natural orthoenstatites and natural diopsides (e.g., Salisbury et al., 1991; Clark, 1999; Hamilton, 2000; Moroz et al., 2007; Moroz et al., 2010; Moroz and Schade, 2011). Thus, the analysis of Reststrahlen bands between 8.5 and $11 \mu \mathrm{m}$ makes it possible to distinguish between orthorhombic and monoclinic pyroxenes, while the $10.7-11.7 \mu \mathrm{m}$ spectral range is useful for discrimination between low-Ca and high-Ca content pyroxenes.

Even though XRPD-measurements have suggested the presence of forsterite within the orthoenstatite sample, we could not detect any features associated with forsterite in the orthoenstatite reflectance spectrum. The Christiansen feature of forsterite is located at $\sim 8.9 \mu \mathrm{m}$ (Salisbury, 1993; Maturilli et al., 2008), which is at significantly longer wavelength than in enstatite but we do not see any shift of the CF in the orthoenstatite compared to the clinoenstatite. Additionally, the spectra of orthoenstatite and clinoenstatite are almost identical between 4 and $8.5 \mu \mathrm{m}$. The spectral behavior of forsterite is very different to that of 


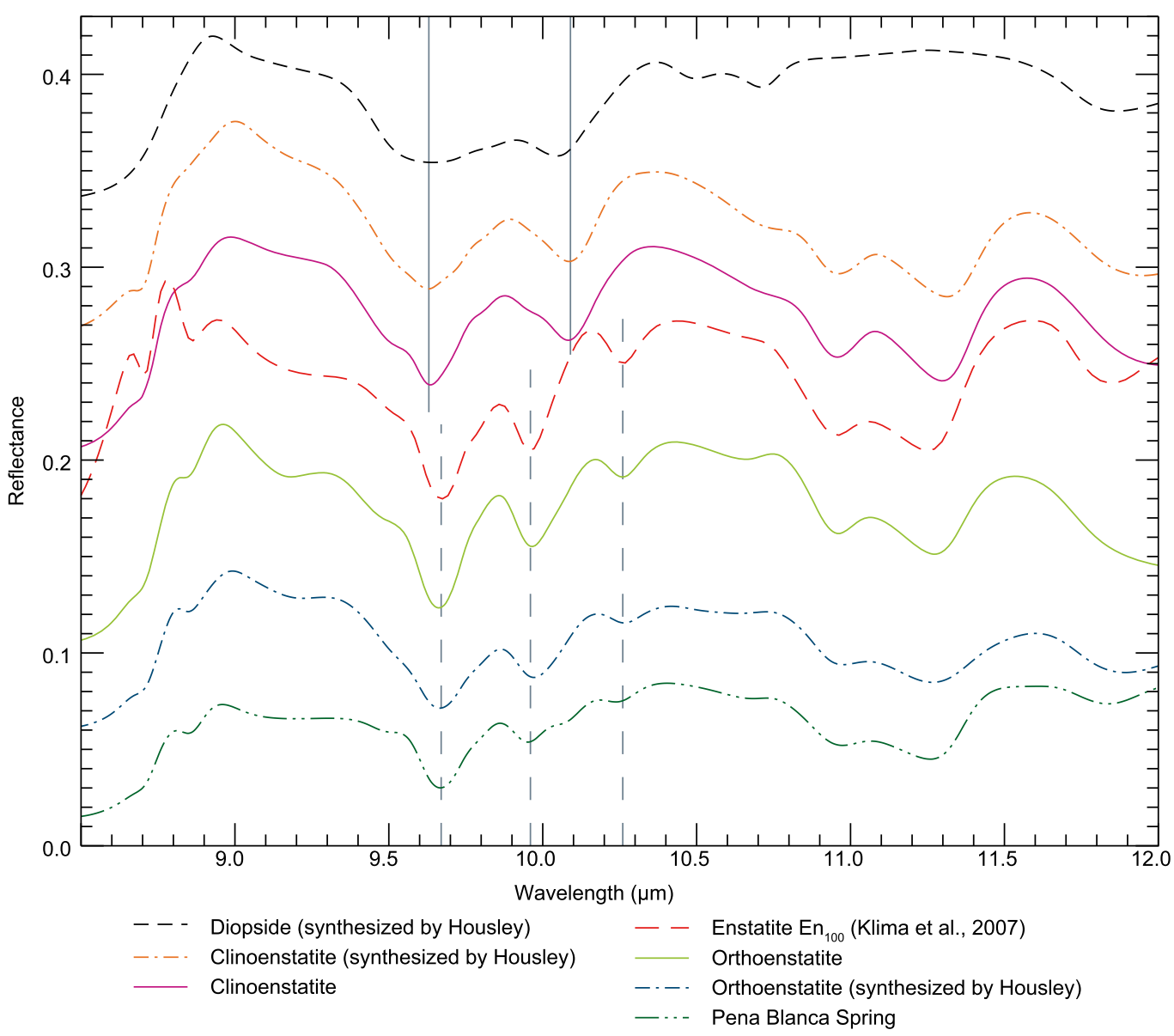

Fig. 9. Differences in the Reststrahlen bands between clinoenstatite and orthoenstatite. Orthoenstatites (this study, Peña Blanca Spring, and $\mathrm{En}_{100}$ from Klima et al., 2007) show two local minima at $9.96 \mu \mathrm{m}$ and at $10.26 \mu \mathrm{m}$. Clinoenstatites and diopside show only one minimum at $10.09 \mu \mathrm{m}$. The minimum between $9.6 \mu \mathrm{m}$ and $9.7 \mu \mathrm{m}$ is shifted between ortho- and clinoenstatites. It is located at $9.63 \mu \mathrm{m}$ in the clinoenstatites and at $9.67 \mu \mathrm{m}$ in the orthoenstatites. Unlike enstatite spectra, the diopside spectrum shows a single broad maximum between 10.7 and $11.8 \mu \mathrm{m}$. Dashed vertical lines mark minima in the orthoenstatite spectra; solid vertical lines mark minima in the clinoenstatite spectra. The enstatite spectrum from Klima et al. (2007) was obtained from the RELAB-database (Reflectance Experiment Laboratory, http://www. planetary.brown.edu/relabdata/) under the sample name "DL-CMP-001". Spectra are offset for clarity. enstatite in this spectral range with forsterite showing several absorption bands between 5 and $6 \mu \mathrm{m}$ and maxima between 6 and $7 \mu \mathrm{m}$ (e.g., Moroz et al., 1996; Mustard and Hays, 1997). In the Reststrahlen bands, the orthoenstatite spectrum shows the same fine structure as Housley's orthoenstatite and the enstatite $\mathrm{En}_{100}$ from Klima et al. (2007) with no indication of the presence of peaks or minima present in the forsterite Reststrahlen bands.

\subsection{Grain size effects}

In the near UV and VIS, the grain size of the samples has crucial influence on the spectral behavior of the samples. A subsample of the orthoenstatite sample was ground for several minutes in an agate mortar to achieve an even smaller grain size. Grain sizes are described in section 2.2. The average maximum diameter of the grains in the orthoenstatite sample decreased from $26 \mu \mathrm{m}$ to $4 \mu \mathrm{m}$ (Table 2). The additional grinding of the orthoenstatite has not induced the transition to clinoenstatite as observed by Lee and Heuer (1987). This is concluded from peak and minima positions in the Reststrahlen bands staying identical to the original orthoenstatite (see section 3.2). The transparency feature (TF) is located between $12 \mu \mathrm{m}$ and $13.5 \mu \mathrm{m}$ and occurs depending on the grain size of the sample. The decrease in grain size of the subsample is evident in reflectance spectra in the substantial increase of the transparency feature and a reduced contrast in the Reststrahlen bands (Fig. 10). The other two spectra with a similarly intense transparency feature are the spectra of Peña Blanca Spring and the enstatite from Klima et al. (2007). The Peña Blanca Spring sample was sieved to $<90 \mu \mathrm{m}$ grain size fraction but the spectrum suggest that the average grain size is much smaller. The $\mathrm{En}_{100}$ from Klima et al. (2007) was sieved to $<45 \mu \mathrm{m}$. The peak of the transparency feature in the spectrum of the additionally ground orthoenstatite is at a slightly shorter wavelength than in the $\mathrm{En}_{100}$ enstatite spectrum and shows a slightly asymmetric shape. The short-wavelength flank is steeper than the long-wavelength flank. Mustard and Hays (1997) observed a systematic shift of the TF reflectance peak to shorter wavelengths, an increasingly asymmetric shape of the TF, and a systematic increase followed by a decrease in peak reflectance as particle size of an olivine sample decreases from 20 to $25 \mu \mathrm{m}$ to $<5 \mu \mathrm{m}$. In the VIS and NIR, the additionally ground orthoenstatite, enstatite $\mathrm{En}_{100}$ from Klima et al. (2007), and Peña Blanca Spring are darker than the other samples, including the diopside, both clinoenstatites, Housley's orthoenstatite, and the original orthoenstatite sample (Fig. 11). The spectra also show a red slope throughout the VIS and near UV and lack the steep drop in the UV (Fig. 12). Additionally, the finer grain size also masks the weak absorption bands between 0.4 and $0.8 \mu \mathrm{m}$ in the orthoenstatite spectrum (Figs. 11 and 12). Both Peña Blanca Spring and the Klima's $E_{100}$ spectra show a weak absorption at $\sim 0.9 \mu \mathrm{m}$. Considering the masking of absorption bands because of the further comminution of the orthoenstatite sample, we assume these absorption features to be stronger than the absorption features in the spectrum of the original orthoenstatite produced in this study. The higher FeO content of $0.06 \mathrm{wt} \%$ reported by Klima et al. (2007) supports this assumption. In the volume scattering regime, reflectance increases with decreasing grain size (Hapke, 1993). The observation of the opposite trend in our orthoenstatite sample is an indicator that grain sizes have become so small that Rayleigh scattering plays an increasingly important role along with volume scattering. Indeed, the majority of grains in our additionally ground orthoenstatite sample have diameters smaller than $2 \mu \mathrm{m}$ (Table 2). Mustard and Hays (1997) observed a similar behavior for a quartz sample. They observed the $<5 \mu \mathrm{m}$ grain size fraction to be darker than the larger grain size fractions. However, we cannot rule out that the 


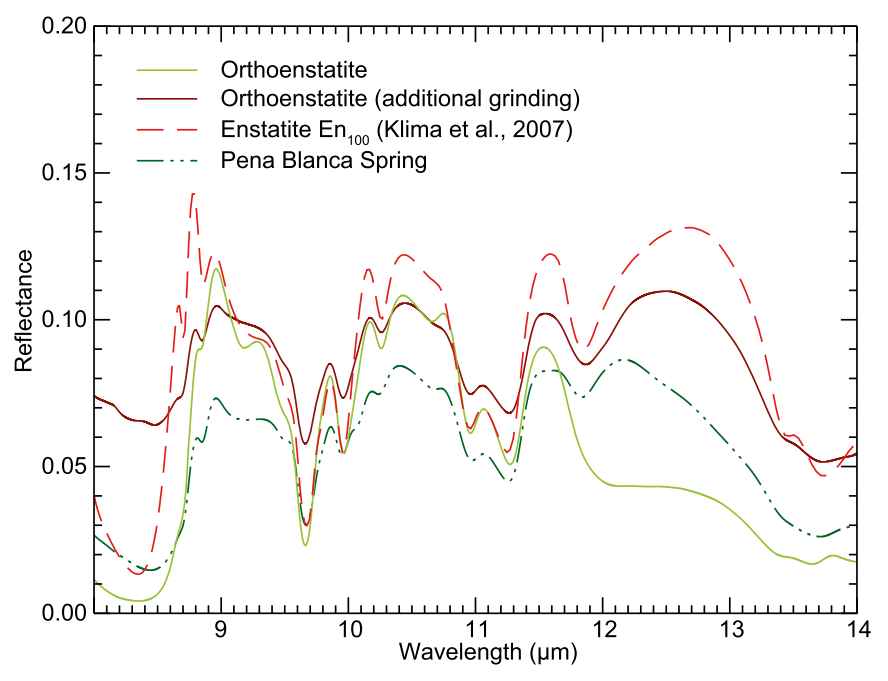

Fig. 10. Reststrahlen bands and transparency features in the spectra of the orthoenstatite sample and an orthoenstatite subsample that was measured after additional grinding of the subsample. The transparency feature is more prominent in the spectrum of the additionally ground subsample with finer grain sizes. The spectra of Peña Blanca Spring and the enstatite $\mathrm{En}_{100}$ from Klima et al. (2007) show similarly pronounced transparency features and are shown for comparison. The transparency feature is the brightest or second brightest peak in this spectral range for all three fine-grained samples. The drastic spectral differences between our samples and the $\mathrm{En}_{100}$ of Klima et al. (2007) in the $8-9 \mu \mathrm{m}$ spectral range are due to the differences in viewing geometry - the RELAB MIR spectra are strongly distorted in this spectra range by significant contributions from phase angles larger than $60^{\circ}$ (Moroz et al., 2010; Moroz and Schade, 2011).

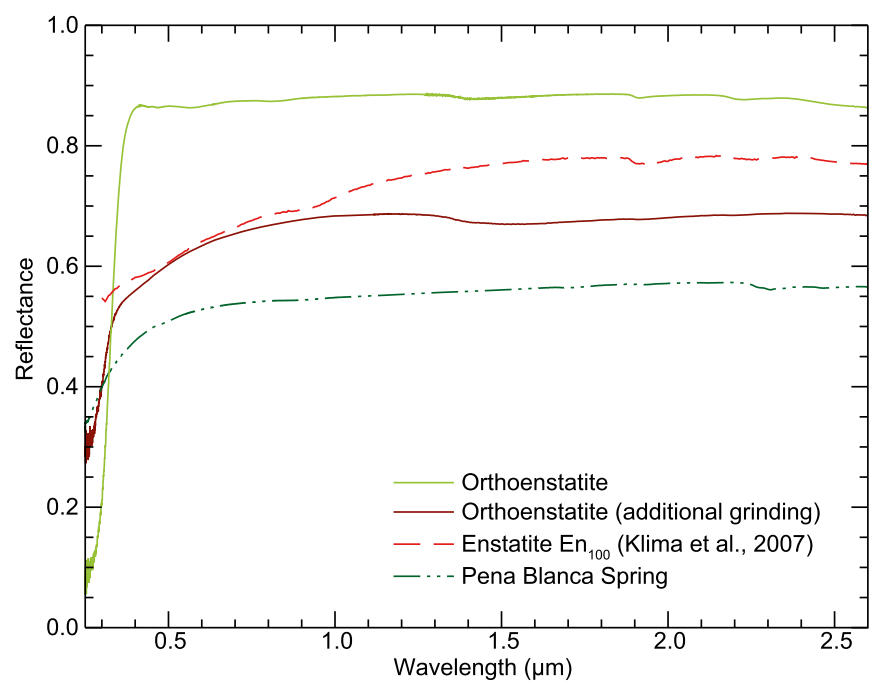

Fig. 11. Decrease in grain size has influenced the overall reflectance level and the VIS and NIR slopes of the orthoenstatite spectrum. The orthoenstatite was remeasured after additional grinding of the sample. Peña Blanca Spring and the enstatite spectra from Klima et al. (2007) are shown for comparison.

spectral behavior of our Peña Blanca Spring sample is also influenced by organic contamination and fine-grained opaque minerals like sulfides resulting in a lower reflectance and redder slope.

\section{Summary}

We developed a method for synthesizing ortho- and clinoenstatite powders in air that can be used to produce larger quantities needed for reflectance spectroscopy. The advantage of our method is the possibility

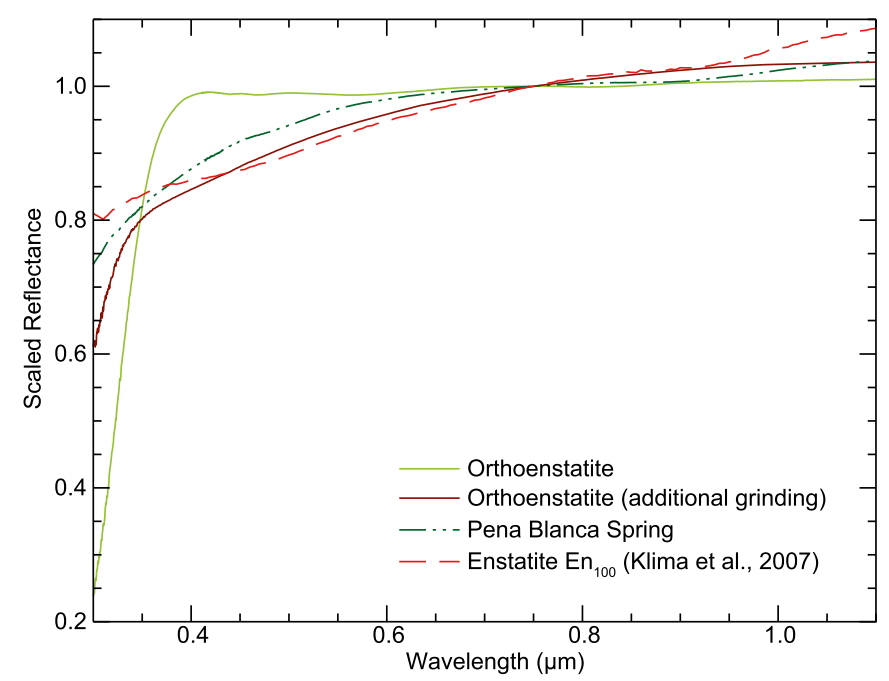

Fig. 12. Decrease in grain size has influenced the VIS slopes of the orthoenstatite spectrum. The orthoenstatite was remeasured after additional grinding of the sample. Peña Blanca Spring and the enstatite spectra from Klima et al. (2007) are shown for comparison. Spectra are scaled to unity at $0.75 \mu \mathrm{m}$.

to produce two polymorphs of enstatite using only a furnace and without having to apply high pressures. This makes the method easily applicable in different laboratories. The orthoenstatite and clinoenstatite are almost Fe-free with $\mathrm{FeO}$ contents below the detection limit of $\sim 0.04 \mathrm{wt} \%$ of the microprobe. The mineralogical compositions of ortho- and clinoenstatite are $\mathrm{En}_{99.9} \mathrm{Fs}_{0.03} \mathrm{Wo}_{0.0}$ and $\mathrm{En}_{99.9} \mathrm{Fs}_{0.05} \mathrm{Wo}_{0.04}$, respectively.

We measured $0.25-17 \mu \mathrm{m}$ biconical reflectance spectra of the two enstatite polymorphs and compared them to reflectance spectra of other nearly Fe-free synthetic pyroxenes (ortho- and clinoenstatite, diopside). All synthetic pyroxene powders were characterized in terms of chemical composition and grain size distribution. The enstatites produced in this study were also characterized by the XRPD technique.

The powders of both enstatite polymorphs (as well as diopside) are very bright and their reflectance spectra between 0.4 and $2.6 \mu \mathrm{m}$ are almost featureless and show nearly flat spectral slopes. Despite the very low contents of $\mathrm{Fe}$ and other transition elements, all spectra show a sharp UV drop-off due to metal-O charge transfer. The UV slopes of the orthoenstatite spectra are significantly steeper than the slopes of the clinoenstatite spectra. The absorption edge in the UV-VIS occurs at longer wavelengths in clinoenstatite spectra than in that of orthoenstatites. Some minor absorption bands are visible in the VIS and NIR. In particular, both clinoenstatite spectra show an absorption band at $\sim 0.9 \mu \mathrm{m}$ due to $\mathrm{Fe}^{2+}$, while another weak broad band at $\sim 1.8 \mu \mathrm{m}$ is seen in the spectra of clinoenstatite produced in this study. These bands are not visible in the orthoenstatite spectra. All reflectance spectra of synthetic pyroxenes show additional weak absorption bands between $0.4 \mu \mathrm{m}$ and $0.9 \mu \mathrm{m}$ due to traces of Fe ions and possibly other transition elements. In general, the UV-NIR spectral range does not provide the possibility for reliable discrimination between two enstatite polymorphs or low-Ca and high-Ca pyroxenes in mineral assemblages with Fe-free or nearly Fe-free pyroxenes.

The MIR spectral range is significantly more informative in terms of remote sensing discrimination between the ortho- and clinoenstatites as well as Fe-free low-Ca and high-Ca pyroxenes. The Christiansen feature in MIR spectra of Fe-free ortho- and clinoenstatites is located at $8.35 \mu \mathrm{m}$. The major difference between the two enstatite polymorphs is seen in the Reststrahlen bands. Orthoenstatite spectra show three reflectance minima at $\sim 10 \mu \mathrm{m}$, while clinoenstatite spectra show only two minima. This can be used to discriminate spectrally between these two polymorphs. As in the case of Fe-bearing pyroxenes, Fe-free high-Ca pyroxenes can be distinguished from low-Ca ones by the presence of an 
unstructured reflectance maximum between 10.7 and $11.7 \mu \mathrm{m}$. Additional spectral differences are observed between 4.5 and $7.5 \mu \mathrm{m}$.

Significantly reducing the grain size of the samples has a major impact on the spectral behavior. Samples with much smaller grain sizes as clearly recognizable due to the transparency feature show a different spectral behavior in the VIS and NIR. The overall reflectance decreases, the slopes in the VNIR become distinctly red, while the weak absorptions visible in the spectra of the coarser-grained samples are obscured, and the UV slope becomes less pronounced.

\section{Implications for remote sensing of solar system objects}

The possibility to discern between orthoenstatite and clinoenstatite on planetary surfaces bears implications on the thermal and shock history of these surfaces. Both polymorphs can form by inversion from protoenstatite. The formation of orthoenstatite requires very slow cooling, while clinoenstatite forms during rapid cooling (Buseck et al., 1980). Inversion from orthoenstatite to clinoenstatite is induced by homogenous shear and/or inhomogenous shear (e.g., shock) or by annealing to moderate or low temperatures (Buseck et al., 1980). Clinoenstatites formed by different processes are found within the meteorite collection and therefore should be present on their respective parent body. In enstatite chondrites, clinoenstatite is observed in unmetamorphosed chondrules suggesting that they formed from liquid droplets by rapid cooling (Reid and Cohen, 1967). Clinoenstatite in enstatite achondrites is found intimately intergrown with orthoenstatite suggesting formation due to stress (Mason, 1968; Reid and Cohen, 1967). The presence of significant and spectroscopically detectable amounts of clinoenstatite on planetary surfaces could point to shock events like impacts or heating with subsequent rapid cooling.

Telescopic surveys of asteroids have shown that E-type asteroids generally show flat to slightly reddish and featureless or weakly featured reflectance spectra and are additionally characterized by high albedos (e.g., Gaffey et al., 1993; Tholen, 1984; Tholen and Barucci, 1989). This indicates that the surface of E-type asteroids is dominated by Fe-free or Fe-poor silicates. They are speculated to be the parent bodies of the aubrite meteorites (e.g., Bell et al., 1989; Clark et al., 2004; Gaffey et al., 1993; Keil, 2010). Dynamical modeling by Fornasier et al. (2007) suggests that the E-type asteroids 2867 Šteins located in the main belt and Near-Earth asteroid 3103 Eger are fragments of an eroded family. They assume the origin of this eroded family to be close to Steins' present location. Their modeling shows a way of delivering material from this former E-type asteroid family in the main belt to Earth. All aubrites except for Shallowater share a common origin on a single parent body that is different to the parent body of the enstatite chondrites (Keil, 1989, 2010). This parent body could have undergone collisional disruption to form the eroded family with subsequent delivery of aubritic material to Earth-crossing orbits.

Due to the atmospheric window at $8-13 \mu \mathrm{m}$ it is possible to perform ground-based telescopic observations of asteroids in the MIR (e.g., Lim et al., 2005; Vernazza et al., 2010). Space-based observations using, e.g., the Spitzer Space Telescope (SST) or the Infrared Space Observatory (ISO) have moved the observed wavelength range to shorter wavelengths in the MIR (e.g., Barucci et al., 2002, 2008; Dotto et al., 2002). Barucci et al. (2008) observed the target of the ESA Rosetta mission Šteins with the SST and collected emissivity spectra between 5.2 and $38 \mu \mathrm{m}$. They compared the resultant data with emissivity spectra of enstatite and the aubrite ALH84007 and concluded that the general behavior of the Šteins spectrum and the positions of the Christiansen feature, Reststrahlen bands, and Transparency feature are similar to those of the enstatite and aubrite spectra. Comparing the spectra of the enstatites synthesized for this study with the Peña Blanca Spring spectrum shows that the samples can be used for compositional modeling with regards to the E-type asteroids either by mathematical models of endmember spectra or by preparing mixtures of samples in the laboratory. Resolving spectral features as fine as the differences between orthoenstatite and clinoenstatite observed during this study is not possible with either ground- or space-based telescopes so far.

Enstatite also occurs on comets as it is found in IDPs of presumably cometary origin (Messenger et al., 2003) and in the dust of comet 81P/Wild 2 collected by the Stardust mission in 2004 (Brownlee et al., 2006; Zolensky et al., 2006). Zolensky et al. (2006) reported that lowand high-Ca pyroxenes are both present in the dust grains recovered from Wild 2 with low-Ca pyroxenes being dominant. Some low-Ca pyroxene grains were shown to be orthopyroxene by synchrotron x-ray diffraction or selected-area electron diffraction but for the majority of the grains discerning between ortho- and clinoenstatite is not possible. The low-Ca pyroxene composition in the recovered cometary dust range from $\mathrm{En}_{52}$ to $\mathrm{En}_{100}$ but the majority of grains have compositions between $\mathrm{En}_{90}$ and $\mathrm{En}_{100}$ (Zolensky et al., 2006). Ground-based IR observations also indicate that enstatite is a major crystalline silicate component of cometary dust (Hanner, 1999; Harker et al., 2002; Wooden et al., 2000, 2005). Thus, synthetic enstatite spectra discussed in this study can be used for interpretation of cometary spectra, for example, reflectance spectra of comet 67P/CG provided by the Visible and Infrared Thermal Imaging Spectrometer (VIRTIS) onboard ESA's Rosetta mission (Capaccioni et al., 2015). The spectra can be included as endmembers into theoretical mixing models aimed at interpreting VIRTIS/Rosetta spectra. Furthermore, the samples can be used as endmemers in laboratory mixtures with other phases in order to characterize the spectral influence of bright crystalline silicate components on spectral properties of the cometary nucleus' surface. In addition, the MIR spectra of our synthetic enstatites can provide useful input for interpretation of future infrared observations of cometary nuclei.

MErcury Surface, Space ENvironment, Geochemistry, and Ranging (MESSENGER) orbital observations showed that very Fe-poor enstatites appear to be major silicate components of Mercury's surface. Analyses of elemental abundances and elemental ratios derived by the X-ray Spectrometer (XRS) indicate that Mercury's surface mineralogy is generally consistent with high-temperature partial melts of enstatite chondrites, being dominated by high-Mg mafic (mostly enstatite) and plagioclase feldspar (calcic and sodic) minerals with smaller amounts of sulfide phases (e.g., Nittler et al., 2011; Stockstill-Cahill et al., 2012; Weider et al., 2012). In particular, Stockstill-Cahill et al. (2012) concluded that enstatite is the most abundant silicate mineral in most locations, except for some Na-rich areas of the northern volcanic plains where plagioclase is more abundant. The lack of detectable NIR absorption bands in MESSENGER's Mercury Atmospheric and Surface Composition Spectrometer (MASCS; McClintock and Lankton, 2007) reflectance spectra suggests that $\mathrm{FeO}$ in Mercury's silicates does not exceed $1.8 \mathrm{wt} \% \mathrm{FeO}$, while some iron should be present in sulfide and metallic form (Izenberg et al., 2014). Moreover, evaluation of $\mathrm{fO}_{2}$ coupled with $\mathrm{fS}_{2}$ in Mercury's magmas, based on the MESSENGER mission results, indicates that $\mathrm{FeO}$ content in silicates ranges from 0.024 to $0.79 \mathrm{wt} \%$ (Zolotov et al., 2013). $\mathrm{FeO}$ contents of synthetic enstatites from our study $(<0.04)$ are within this range, suggesting that our enstatite samples are suitable analogue materials of Mercury's silicates. Thus, their reflectance spectra reported and discussed in this study can serve as useful reference for interpretation of MESSENGER VNIR spectra as well as the future MIR emissivity spectra of Mercury which will be acquired by the MErcury Radiometer and Thermal Infrared Spectrometer (MERTIS) instrument onboard ESA's BepiColombo mission.

Our results imply that very low $(<0.04$ wt\%) FeO contents in Mercury's enstatites would be sufficient to explain the presence of the UV downturn reported in MASCS reflectance spectra of Mercury's surface (Izenberg et al., 2014; McClintock et al., 2008). Bright surface areas on Mercury show flatter VIS-NIR spectral slopes and deeper UV absorption bands than darker terrains, suggesting lower abundances of opaque components and higher abundances of low-Fe bright silicates (Izenberg et al., 2014). The ratios of the spectra of these bright areas and the average Mercury surface spectrum show the UV absorption downturn shortward of $0.4 \mu \mathrm{m}$ to be likely associated with Fe ions in silicates. The 
position of the UV absorption edge is generally consistent with that of our synthetic enstatites with $<0.04 \mathrm{wt} \% \mathrm{FeO}$, suggesting that $\mathrm{FeO}$ contents in Mercury's enstatites are hardly higher than this value. Reflectance spectra of plagioclases show UV-absorption edges at shorter wavelengths (Cloutis et al., 2008). The presence of the $0.4-\mu \mathrm{m}$ absorption edge in the ratioed spectra of Mercury's bright areas suggest some contribution from large silicate grains together with fine grains, since the reflectance spectrum of our very fine-grained (additionally ground) enstatite is characterized by a significant red slope also at wavelengths longer than $0.4 \mu \mathrm{m}$.

MERTIS onboard ESA's BepiColombo spacecraft will perform global mineralogical mapping of Mercury's surface in the MIR spectral range between 7 and $14 \mu \mathrm{m}$ with high spectral and spatial resolution (Hiesinger et al., 2010). Interpretation of the MERTIS spectra will require endmember spectra of suitable mineral analogues with appropriate ranges of grain sizes. Our MIR reflectance spectra of synthetic high-Mg pyroxenes provide useful criteria helping to distinguish between ortho- and clinoenstatites, as well as low-Ca and high-Ca pyroxenes. In addition, our data show that even very fine-grained enstatites can be identified in the MERTIS spectral range. Unlike RELAB MIR spectra (e.g., enstatites from Klima et al., 2007) or all mineral spectra from Salisbury et al. (1991) measured at grazing viewing geometries, the biconical reflectance spectra reported here are free of distortions related to high phase angles, and thus can be converted to emissivity and compared to normal emissivity that will be measured by the MERTIS instrument (Moroz et al., 2010; Moroz and Schade, 2011). However, one should take into account effects of high temperatures typical of Mercury's surface, as well as possible surface alteration effects like space weathering and impact-induced vitrification. It is likely that the bright areas, where fresh crater materials are exposed, will be the most promising targets for successful compositional characterization of the silicate components of Mercury's surface in the MIR spectral range.

\section{Acknowledgments}

We thank Dr. Robert Housley for kindly providing his samples of synthetic orthoenstatite, clinoenstatite, and diopside. We also like to thank Dr. Jasper Berndt and Beate Schmitte for help with the microprobe measurements and Dr. Peter Schmid-Beurmann for help with the XRD measurements. K.M. acknowledges DLR grant D/957/67229379. L.M. acknowledges the DFG grant MO 3007/1-1.

\section{References}

Adams, J.B., 1974. Visible and near-infrared diffuse reflectance spectra of pyroxenes as applied to remote sensing of solid objects in the solar system. J. Geophys. Res. 79, 4829-4836.

Allen, E.T., Wright, F.E., Clement, J.K., 1906. Minerals of the composition $\mathrm{MgSiO}_{3}$; A case of tetramorphism. Am. J. Sci. 22, 385-438.

Barucci, M., Dotto, E., Brucato, J., Müller, T., Morris, P., Doressoundiram, A., Fulchignoni, M., De Sanctis, M., Owen, T., Crovisier, J., 2002. 10 Hygiea: ISO infrared observations. Icarus 156, 202-210.

Barucci, M.A., Fornasier, S., Dotto, E., Lamy, P.L., Jorda, L., Groussin, O., Brucato, J.R., Carvano, J., Alvarez-Candal, A., Cruikshank, D., Fulchignoni, M., 2008. Asteroids 2867 Steins and 21 Lutetia: surface composition from far infrared observations with the Spitzer space telescope. Astron. Astrophys. 477, 665-670.

Bell, J.F., Davis, D.R., Hartmann, W.K., Gaffey, M.J., 1989. Asteroids: the big picture. In: Binzel, R.P., Gehrels, T., Matthews, M.S. (Eds.), Asteroids II. The University of Arizona Press, Tucson, pp. 921-945.

Bishop, J.L., Lane, M.D., Dyar, M.D., Brown, A.J., 2008. Reflectance spectroscopy study of four groups of phyllosilicates: smectites, kaolinite-serpentines, chlorites and micas. Clay Miner. 43, 35-54.

Blazey, K., 1977. Optical absorption of MgO: Fe. J. Phys. Chem. Solid. 38, 671-675. Boyd, F.R., Schairer, J.F., 1964. The system $\mathrm{MgSiO}_{3}-\mathrm{CaMgSi}_{2} \mathrm{O}_{6}$. J. Petrol. 5, 275-309.

Brownlee, D., Tsou, P., Aléon, J., Alexander, C.M.D., Araki, T., Bajt, S., Baratta, G.A., Bastien, R., Bland, P., Bleuet, P., 2006. Comet 81P/Wild 2 under a microscope. Science 314, 1711-1716.

Burns, R.G., 1993a. Origin of electronic spectra of minerals in the visible to near-infrared region. In: Pieters, C.M.P., Englert, P.A.J. (Eds.), Topics in Remote Sensing, Volume 4, Remote Geochemical Analysis: Elemental and Mineralogical Composition. Cambridge University Press, Cambridge, pp. 3-29.
Burns, R.G., 1993b. Mineralogical Applications of Crystal Field Theory, second ed. Cambridge University Press, Cambridge.

Buseck, P.R., Nord, G.L., Veblen, D.R., 1980. Subsolidus phenomena in pyroxenes. In: Prewitt, C.T. (Ed.), Reviews in Mineralogy, Volume 7, Pyroxenes. Mineralogical Society of America, pp. 117-211.

Capaccioni, F., Coradini, A., Filacchione, G., Erard, S., Arnold, G., Drossart, P., De Sanctis, M.C., Bockelee-Morvan, D., Capria, M.T., Tosi, F., Leyrat, C., Schmitt, B., Quirico, E., Cerroni, P., Mennella, V., Raponi, A., Ciarniello, M., McCord, T., Moroz, L., Palomba, E., Ammannito, E., Barucci, M.A., Bellucci, G., Benkhoff, J., Bibring, J.P., Blanco, A., Blecka, M., Carlson, R., Carsenty, U., Colangeli, L., Combes, M., Combi, M., Crovisier, J., Encrenaz, T., Federico, C., Fink, U., Fonti, S., Ip, W.H., Irwin, P., Jaumann, R., Kuehrt, E., Langevin, Y., Magni, G., Mottola, S., Orofino, V., Palumbo, P., Piccioni, G., Schade, U., Taylor, F., Tiphene, D., Tozzi, G.P., Beck, P., Biver, N., Bonal, L., Combe, J.-P., Despan, D., Flamini, E., Fornasier, S., Frigeri, A., Grassi, D., Gudipati, M., Longobardo, A., Markus, K., Merlin, F., Orosei, R., Rinaldi, G., Stephan, K., Cartacci, M., Cicchetti, A., Giuppi, S., Hello, Y., Henry, F., Jacquinod, S., Noschese, R., Peter, G., Politi, R., Reess, J.M., Semery, A., 2015. The organic-rich surface of comet 67P/Churyumov-Gerasimenko as seen by VIRTIS/ Rosetta. Science 347 aaa0628.

Christiansen, C., 1884. Untersuchungen über die optischen Eigenschaften von fein vertheilten Körpern. Ann. Phys. 259, 298-306.

Clark, B.E., Bus, S.J., Rivkin, A.S., McConnochie, T., Sanders, J., Shah, S., Hiroi, T., Shepard, M., 2004. E-type asteroid spectroscopy and compositional modeling. J. Geophys. Res. Planets 109. E02001.

Clark, R.N., King, T.V.V., Klejwa, M., Swayze, G.A., 1990. High spectral resolution reflectance spectroscopy of minerals. J. Geophys. Res.: Solid Earth 95, 12653-12680.

Clark, R.N., 1999. Spectroscopy of rocks and minerals, and principles of spectroscopy. In: Rencz, A.N. (Ed.), Manual of Remote Sensing, Volume 3, Remote Sensing for the Earth Sciences. John Wiley and Sons, New York, pp. 3-58.

Cloutis, E.A., 2002. Pyroxene reflectance spectra: minor absorption bands and effects of elemental substitutions. J. Geophys. Res. Planets 107, 5039.

Cloutis, E.A., Gaffey, M.J., 1991. Pyroxene spectroscopy revisited: spectral-compositional correlations and relationship to geothermometry. J. Geophys. Res. Planets 96, 22809-22826.

Cloutis, E.A., McCormack, K.A., Bel III, J.F., Hendrix, A.R., Bailey, D.T., Craig, M.A., Mertzman, S.A., Robinson, M.S., Riner, M.A., 2008. Ultraviolet spectral reflectance properties of common planetary minerals. Icarus 197, 321-347.

Conel, J.E., 1969. Infrared emissivities of silicates: experimental results and a cloudy atmosphere model of spectral emission from condensed particulate mediums. J. Geophys. Res. 74, 1614-1634.

Dotto, E., Barucci, M., Müller, T., Brucato, J., Fulchignoni, M., Mennella, V., Colangeli, L., 2002. ISO observations of low and moderate albedo asteroids: PHT-P and PHT-S results. Astron. Astrophys. 393, 1065-1072.

Fornasier, S., Marzari, F., Dotto, E., Barucci, M.A., Migliorini, A., 2007. Are the E-type asteroids (2867) Steins, a target of the Rosetta mission, and NEA (3103) Eger remnants of an old asteroid family? Astron. Astrophys. 474, L29-L32.

Gaffey, M.J., Burbine, T.H., Binzel, R.P., 1993. Asteroid spectroscopy - progress and perspectives. Meteoritics 28, 161-187.

Hamilton, V.E., 2000. Thermal infrared emission spectroscopy of the pyroxene mineral series. J. Geophys. Res. Planets 105, 9701-9716.

Hanner, M.S., 1999. The silicate material in comets. Space Sci. Rev. 90, 99-108.

Hapke, B., 1993. Theory of Reflectance and Emittance Spectroscopy. Cambridge University Press, Cambridge.

Harker, D.E., Wooden, D.H., Woodward, C.E., Lisse, C.M., 2002. Grain properties of comet C/1995 O1 (Hale-Bopp). Astrophys. J. 580, 579.

Hazen, R.M., Bell, P.M., Mao, H.K., 1978. Effects of compositional variation on absorption spectra of lunar pyroxenes. In: Lunar and Planetary Science Conference 9, pp. 2919-2934.

Hiesinger, H., Helbert, J., Mertis Co-I Team, 2010. The Mercury radiometer and thermal infrared spectrometer (MERTIS) for the BepiColombo mission. Planet. Space Sci. 58, $144-165$.

Izenberg, N.R., Klima, R.L., Murchie, S.L., Blewett, D.T., Holsclaw, G.M., McClintock, W.E., Malaret, E., Mauceri, C., Vilas, F., Sprague, A.L., Helbert, J., Domingue, D.L., Head III, J.W., Goudge, T.A., Solomon, S.C., Hibbitts, C.A., Dyar, M.D., 2014. The low-iron, reduced surface of Mercury as seen in spectral reflectance by MESSENGER. Icarus 228, 364-374.

Keil, K., 1989. Enstatite meteorites and their parent bodies. Meteoritics 24, 195-208.

Keil, K., 2010. Enstatite achondrite meteorites (aubrites) and the histories of their asteroidal parent bodies. Chemie der Erde - Geochemistry 70, 295-317.

Keller, H.U., Barbieri, C., Koschny, D., Lamy, P., Rickman, H., Rodrigo, R., Sierks, H., A'Hearn, M.F., Angrilli, F., Barucci, M.A., Bertaux, J.L., Cremonese, G., Da Deppo, V., Davidsson, B., De Cecco, M., Debei, S., Fornasier, S., Fulle, M., Groussin, O. Gutierrez, P.J., Hviid, S.F., Ip, W.H., Jorda, L., Knollenberg, J., Kramm, J.R., Kuhrt, E., Kuppers, M., Lara, L.M., Lazzarin, M., Moreno, J.L., Marzari, F., Michalik, H., Naletto, G., Sabau, L., Thomas, N., Wenzel, K.P., Bertini, I., Besse, S., Ferri, F., Kaasalainen, M., Lowry, S., Marchi, S., Mottola, S., Sabolo, W., Schroder, S.E., Spjuth, S., Vernazza, P., 2010. E-Type asteroid (2867) Šteins as imaged by OSIRIS on board Rosetta. Science 327, 190-193.

Klima, R.L., Pieters, C.M., Dyar, M.D., 2007. Spectroscopy of synthetic Mg-Fe pyroxenes I: spin-allowed and spin-forbidden crystal field bands in the visible and near-infrared. Meteoritics Planet Sci. 42, 235-253.

Klima, R.L., Dyar, M.D., Pieters, C.M., 2011. Near-infrared spectra of clinopyroxenes: effects of calcium content and crystal structure. Meteoritics Planet Sci. 46, 379-395.

Lee, W.E., Heuer, A.H., 1987. On the polymorphism of enstatite. J. Am. Ceram. Soc. 70, 349-360. 
Lim, L.F., McConnochie, T.H., Bell, J.F., Hayward, T.L., 2005. Thermal infrared (8-13 $\mu \mathrm{m})$ spectra of 29 asteroids: the cornell mid-infrared asteroid spectroscopy (MIDAS) survey. Icarus 173, 385-408.

Lonsdale, J.T., 1947. The Peña Blanca spring meteorite, brewster county, Texas. Am. Mineral. 32, 354-364.

Lyon, R.J.P., 1964. Analysis of rocks by spectral infrared emission (8-25 microns). Econ. Geol. 60, 717-736.

Mason, B., 1966. The enstatite chondrites. Geochem. Cosmochim. Acta 30, 23-39.

Mason, B., 1968. Pyroxene in meteorites. Lithos 1, 1-11.

Maturilli, A., Helbert, J., Moroz, L., 2008. The Berlin emissivity database (BED). Planet. Space Sci. 56, 420-425.

McClintock, W.E., Izenberg, N.R., Holsclaw, G.M., Blewett, D.T., Domingue, D.L., Head, J.W., Helbert, J., McCoy, T.J., Murchie, S.L., Robinson, M.S., Solomon, S.C., Sprague, A.L., Vilas, F., 2008. Spectroscopic observations of Mercury's surface reflectance during MESSENGER's first Mercury flyby. Science 321, 62-65.

McClintock, W.E., Lankton, M.R., 2007. The Mercury atmospheric and surface composition spectrometer for the MESSENGER mission. Space Sci. Rev. 131, 481-521.

Messenger, S., Keller, L.P., Stadermann, F.J., Walker, R.M., Zinner, E., 2003. Samples of stars beyond the solar system: silicate grains in interplanetary dust. Science 300, 105-108.

Moroz, L.V., Fisenko, A.V., Semjonova, L.F., Pieters, C.M., Korotaeva, N.N., 1996. Optical effects of regolith processes on $\mathrm{S}$ asteroids as simulated by laser shots on ordinary chondrite and other mafic materials. Icarus 122, 366-382.

Moroz, L.V., Maturilli, A., Helbert, J., Sasaki, S., Bischoff, A., Jessberger, E.K., 2007. Mercury analogue materials: spectral reflectance, its comparison with TIR spectral emission, and a space weathering simulation experiment. In: Lunar and Planetary Science Conference 38. \#1741.

Moroz, L.V., Schade, U., Maturilli, A., Helbert, J., D'Amore, M., Rout, S.S., Bischoff, A., Hiesinger, H., 2010. Spectral reflectance library of Mercury analogue materials and the role of viewing geometry in analysis of remote TIR emission spectra. In: European Planetary Science Congress, EPSC2010-P2745.

Moroz, L.V., Schade, U., 2011. Effects of viewing geometry on thermal infrared spectra of planetary surfaces: the case of enstatite. In: European Planetary Science CongressDivision for Planetary Science of the American Astronomical Society Joint Meeting, EPSC-DPS2011-1098.

Morris, R.V., Lauer, H.V., 1990. Matrix effects for reflectivity spectra of dispersed nanophase (superparamagnetic) hematite with application to Martian spectral data. J. Geophys. Res.: Solid Earth 95, 5101-5109.

Morris, R.V., Lauer, H.V., Lawson, C.A., Gibson, E.K., Nace, G.A., Stewart, C., 1985. Spectral and other physicochemical properties of submicron powders of hematite $(\alpha-\mathrm{Fe} 2 \mathrm{O} 3)$, maghemite $(\gamma$-Fe2O3), magnetite (Fe3O4), goethite $(\alpha$-FeOOH$)$, and lepidocrocite $(\gamma-\mathrm{FeOOH})$. J. Geophys. Res.: Solid Earth 90, 3126-3144.

Mustard, J.F., Hays, J.E., 1997. Effects of hyperfine particles on reflectance spectra from 0.3 to $25 \mu \mathrm{m}$. Icarus $125,145-163$.

Nittler, L.R., Starr, R.D., Weider, S.Z., McCoy, T.J., Boynton, W.V., Ebel, D.S., Ernst, C.M., Evans, L.G., Goldsten, J.O., Hamara, D.K., Lawrence, D.J., McNutt, R.L., Schlemm, C.E., Solomon, S.C., Sprague, A.L., 2011. The major-element composition of Mercury's surface from MESSENGER X-ray spectrometry. Science 333, 1847-1850.

Pieters, C.M., Englert, P.A., 1993. Remote Geochemical Analysis, Volume 4: Elemental and Mineralogical Composition. Cambridge University Press, Cambridge.

Reid, A.M., Cohen, A.J., 1967. Some characteristics of enstatite from enstatite achondrites. Geochem. Cosmochim. Acta 31, 661-672.

Robinson, P., 1980. The composition space of terrestrial pyroxenes; internal and external limits. Rev. Mineral. Geochem. 7, 419-494.

Salisbury, J.W., Walter, L.S., Vergo, N., D'Aria, D.M., 1991. Infrared (2.1-25 Mm) Spectra of Minerals. Johns Hopkins University Press, Baltimore.

Salisbury, J.W., 1993. Mid-infrared spectroscopy: laboratory data. In: Pieters, C.M.P., Englert, P.A.J. (Eds.), Topics in Remote Sensing, Volume 4, Remote Geochemical
Analysis: Elemental and Mineralogical Composition. Cambridge University Press, Cambridge, pp. 79-98.

Salisbury, J.W., Walter, L.S., 1989. Thermal infrared (2.5-13.5 $\mu \mathrm{m})$ spectroscopic remote sensing of igneous rock types on particulate planetary surfaces. J. Geophys. Res.: Solid Earth 94, 9192-9202.

Sarver, J.F., Hummel, F.A., 1962. Stability relations of magnesium metasilicate polymorphs. J. Am. Ceram. Soc. 45, 153-156.

Schneider, C.A., Rasband, W.S., Eliceiri, K.W., 2012. NIH Image to ImageJ: 25 years of image analysis. Br. J. Pharmacol. 9, 671-675.

Smyth, J.R., 1974. Experimental study on the polymorphism of enstatite. Am. Mineral. $59,345-352$.

Stockstill-Cahill, K.R., McCoy, T.J., Nittler, L.R., Weider, S.Z., Hauck, S.A., 2012. Magnesium-rich crustal compositions on Mercury: implications for magmatism from petrologic modeling. J. Geophys. Res. Planets 117. E00L15.

Straub, D.A.W., Burns, R.G., Pratt, S.F., 1991. Spectral signature of oxidized pyroxenes: implications to remote sensing of terrestrial planets. J. Geophys. Res. Planets 96, 18819-18830.

Sunshine, J.M., Pieters, C.M., Pratt, S.F., 1990. Deconvolution of mineral absorption bands: an improved approach. J. Geophys. Res.: Solid Earth 95, 6955-6966.

Tholen, D.J., 1984. Asteroid Taxonomy from Cluster Analysis of Photometry. University of Arizona, Tucson.

Tholen, D.J., Barucci, M.A., 1989. Asteroid taxonomy. In: Binzel, R.P., Gehrels, T., Matthews, M.S. (Eds.), Asteroids II. The University of Arizona Press, Tucson, pp. 298-315.

Vernazza, P., Carry, B., Emery, J., Hora, J.L., Cruikshank, D., Binzel, R.P., Jackson, J., Helbert, J., Maturilli, A., 2010. Mid-infrared spectral variability for compositionally similar asteroids: implications for asteroid particle size distributions. Icarus 207, 800-809.

Vincent, R.K., Hunt, G.R., 1968. Infrared reflectance from mat surfaces. Appl. Optic. 7, 53-59.

Weider, S.Z., Nittler, L.R., Starr, R.D., McCoy, T.J., Stockstill-Cahill, K.R., Byrne, P.K., Denevi, B.W., Head, J.W., Solomon, S.C., 2012. Chemical heterogeneity on Mercury's surface revealed by the MESSENGER X-Ray Spectrometer. J. Geophys. Res. Planets 117. E00L05.

Wooden, D., Harker, D., Brearley, A., 2005. Thermal processing and radial mixing of dust: evidence from comets and primitive chondrites. In: Krot, A.N., Scott, E.R.D., Reipurth, B. (Eds.), Chondrites and the Protoplanetary Disk, Astronomical Society of the Pacific Conference Series, vol. 341, pp. 774-808.

Wooden, D.H., Butner, H.M., Harker, D.E., Woodward, C.E., 2000. Mg-rich silicate crystals in comet Hale-Bopp: ISM relics or solar nebula condensates? Icarus 143, $126-137$.

Zolensky, M.E., Zega, T.J., Yano, H., Wirick, S., Westphal, A.J., Weisberg, M.K., Weber, I., Warren, J.L., Velbel, M.A., Tsuchiyama, A., Tsou, P., Toppani, A., Tomioka, N., Tomeoka, K., Teslich, N., Taheri, M., Susini, J., Stroud, R., Stephan, T., Stadermann, F.J., Snead, C.J., Simon, S.B., Simionovici, A., See, T.H., Robert, F., Rietmeijer, F.J.M., Rao, W., Perronnet, M.C., Papanastassiou, D.A., Okudaira, K., Ohsumi, K., Ohnishi, I., Nakamura-Messenger, K., Nakamura, T., Mostefaoui, S., Mikouchi, T., Meibom, A., Matrajt, G., Marcus, M.A., Leroux, H., Lemelle, L., Le, L., Lanzirotti, A., Langenhorst, F., Krot, A.N., Keller, L.P., Kearsley, A.T., Joswiak, D., Jacob, D., Ishii, H., Harvey, R., Hagiya, K., Grossman, L., Grossman, J.N., Graham, G.A., Gounelle, M., Gillet, P., Genge, M.J., Flynn, G., Ferroir, T., Fallon, S., Ebel, D.S., Dai, Z.R., Cordier, P., Clark, B., Chi, M., Butterworth, A.L., Brownlee, D.E., Bridges, J.C., Brennan, S., Brearley, A., Bradley, J.P., Bleuet, P., Bland, P.A., Bastien, R., 2006. Mineralogy and petrology of comet 81P/Wild 2 nucleus samples. Science 314, 1735-1739.

Zolotov, M.Y., Sprague, A.L., Hauck, S.A., Nittler, L.R., Solomon, S.C., Weider, S.Z., 2013. The redox state, FeO content, and origin of sulfur-rich magmas on Mercury. J. Geophys. Res. Planets 118, 138-146. 